\title{
The control of sexual differentiation of the reproductive system and brain
}

\author{
C A Wilson ${ }^{1,2}$ and D C Davies ${ }^{1}$ \\ ${ }^{1}$ Departments of Basic Medical Sciences, ${ }^{2}$ Clinical Developmental Sciences, St George's, University of London, \\ Cranmer Terrace, Tooting, London SW17 ORE, UK
}

Correspondence should be addressed to C A Wilson; Email: cwilson@sgul.ac.uk

\begin{abstract}
This review summarizes current knowledge of the genetic and hormonal control of sexual differentiation of the reproductive system, brain and brain function. While the chromosomal regulation of sexual differentiation has been understood for over 60 years, the genes involved and their actions on the reproductive system and brain are still under investigation. In 1990, the predicted testicular determining factor was shown to be the $S R Y$ gene. However, this discovery has not been followed up by elucidation of the actions of SRY, which may either stimulate a cascade of downstream genes, or inhibit a suppressor gene. The number of other genes known to be involved in sexual differentiation is increasing and the way in which they may interact is discussed. The hormonal control of sexual differentiation is well-established in rodents, in which prenatal androgens masculinize the reproductive tract and perinatal oestradiol (derived from testosterone) masculinizes the brain. In humans, genetic mutations have revealed that it is probably prenatal testosterone that masculinizes both the reproductive system and the brain. Sexual differentiation of brain structures and the way in which steroids induce this differentiation, is an active research area.

The multiplicity of steroid actions, which may be specific to individual cell types, demonstrates how a single hormonal regulator, e.g. oestradiol, can exert different and even opposite actions at different sites. This complexity is enhanced by the involvement of neurotransmitters as mediators of steroid hormone actions. In view of current environmental concerns, a brief summary of the effects of endocrine disruptors on sexual differentiation is presented.
\end{abstract}

Reproduction (2007) 133 331-359

\section{Sexual differentiation of the reproductive system}

\section{Introduction}

The concept of hormonal regulation of sexual differentiation of the mammalian reproductive system was established in the late 1940 s by Jost. The original paradigm was based on Jost's classic experiments (see Jost et al. 1973), in which testis were removed from foetal male rabbits, inducing a female phenotype at birth. In contrast, transplantation of testis into female embryos induced a male phenotype. The early foetus has the potential to be either male or female and possesses not only an undifferentiated gonadal ridge, but also 'precursors' for both the female (Mullerian) and male (Wolfian) reproductive tracts. Jost suggested that under the influence of the $\mathrm{Y}$ chromosome, the undifferentiated genital ridge develops into testis and in its absence, ovaries form by default. Once the testis are formed, they secrete anti-Mullerian hormone $(\mathrm{AMH}$; also known as Mullerian inhibitory substance), which induces regression of the Mullerian tract and they also produce testosterone, which stimulates development of the Wolfian tract. In the absence of testis and thus, AMH and testosterone, the Mullerian tract develops and the Wolfian tract regresses. Thus, Jost established that male sexual development requires hormonal control and that the female reproductive system develops in the absence of these hormones (Jost et al. 1973).

This basic pattern of hormonal regulation of sexual development has been largely confirmed over the ensuing years, with some extensions and modifications that will be detailed later in this review. Advances in molecular biology have recently highlighted the importance and complexity of chromosomal and genetic regulation of sexual differentiation. Therefore, the regulation of sexual differentiation can be subdivided into chromosomal, genetic and hormonal stages, each influencing the next and resulting not only in sex differences in the reproductive system, but also in the brain. Together, the sex differences in the morphological 
and functional phenotype of the body and brain underlie gender identity, sexual orientation, sexual behaviour and differences in certain non-reproductive behaviours and cognitive functions. In this review, the genetic as well as a more detailed description of the hormonal control of the sexual differentiation of the reproductive system and brain will be presented. The role of certain neurotransmitters in the regulation of sexual differentiation will also be considered. This review largely focuses on experiments carried out on rodents, but wherever possible, comparison is made with data from humans.

\section{Development of the male reproductive system}

\section{Chromosomal sex}

In mammals, sexual differentiation fundamentally results from chromosomal differences, because males (typically $46 \mathrm{XY}$ ) and females (46XX) are defined by the presence or absence of a Y chromosome (see Fleming \& Vilain 2004). Genetic sex is determined at the time of fertilization by the entry of $\mathrm{a} X$ or $\mathrm{Y}$ chromosome from the sperm pronucleus into the pronucleus of the oocyte (Marshall Graves 2000). The mammalian X chromosome is large, bearing 3000-4000 genes and comparison with primitive mammals such as monotremes (egg-laying mammals), indicates that the genes on the long arm of the $X$ chromosome (the $X$ conserved region) are 170 million years old. The rest of the $X$ chromosome has been added more recently and is perhaps derived from chromosomes 1 or 5 (the $X$ added region). Evidence exists to suggest that the $X$ and $Y$ chromosomes were originally homologous, but the $Y$ chromosome has been degraded over 200 million years of mammalian evolution, such that both the $\mathrm{Y}$ conserved and $\mathrm{Y}$ added regions are greatly reduced in size and gene content. The human $Y$ chromosome now bears only 33 genes, with the rest of the chromosome comprising repetitive sequences with unknown function. Only the two tips of the $\mathrm{Y}$ chromosome (one bearing 9 and the other 4 genes; pseudoautosomal regions 1 and 2 respectively) are homologous with similar parts of the $\mathrm{X}$ chromosome. The majority of genes on the $\mathrm{Y}$ chromosome are expressed in the embryonic genital ridge and are concerned with development of the testis and spermatogenesis (Marshall Graves 2000).

\section{Genetic sex}

The process of sexual differentiation begins almost immediately after conception, because as early as day 2 post-fertilization, male embryos comprise more cells and have higher metabolic activity than female embryos. Sex differences in size (males $>$ females) are present in the blastocyst (mice) and zygote (humans), as a result of the accelerating effect of the $Y$ and the retarding effect of the X chromosomes (Mittwoch 2000). However, in the early stages of development, the foetus' phenotype is reproductively bipotent, because the genital ridge is undifferentiated and can develop into testis or ovaries. The ridge itself develops under the influence of several genes e.g. GATA4, LHX9, L1M1 and particularly WT1 (Wilms Tumour 1) and SF1 (steroidogenic factor gene 1) both of which can be detected earlier in development than the others (Viger et al. 2005). n.b. we are following the convention of using upper case letters for human genes and lower case for rodent genes.

The defining sex-determining event is the differentiation of the genital ridge into testis with the formation of Sertoli cells, which only occurs in the presence of a $Y$ chromosome. Testicular differentiation is tightly correlated with the high level of cell proliferation that occurs in the male embryo (Mittwoch 2000). In the early 1950s, the existence of a testis determining factor (TDF) on the $Y$ chromosome, which initiates the masculinization of the genital ridge was predicted (see Jost et al. 1973). Two candidate genes were SRY and ZFY, with the former being confirmed as TDF following mutation analysis in humans and due to its wide distribution across species (Maxson 1997, Marshall Graves 2000). SRY was first characterized and cloned by Sinclair et al. (1990). SRY can be detected in the genital ridge soon after its formation and SRY expression increases under the positive control of WTI, SFI and GATA4 amongst many others genes (Fleming \& Vilain 2004). Once sexual differentiation of the genital ridge has occurred, SRY levels fall (Koopman 2001, Park \& Jameson 2005). In mice, the Sry gene was initially thought to be selectively expressed in the genital ridge, but more recently its expression has also been demonstrated in the brain (Mayer et al. 2000). SRY is expressed in many human tissues (Koopman 2001).

The $S R Y$ gene expresses a transcription factor containing a high mobility group (HMG) domain, which allows it to bind to and induce bending of its target DNA, presumably exposing new binding sites to other nuclear proteins. This appears to be essential for normal functioning of the $S R Y$ gene, because sexual abnormalities are associated with HMG mutations (Fleming \& Vilain 2004). Sex reversal can occur if the $S R Y$ gene is transposed onto the $\mathrm{X}$ chromosome or if it is absent from the $Y$ chromosome; these abnormalities can occur naturally (Vilain \& McCabe 1998) and more recently have been induced in mice experimentally, resulting in XY females and XX males (Maxson 1997, Arnold et al. 2004). Although as yet unproven, it is thought that SRY together with SF1 as a synergistic factor, activates a cascade of other genes, which are required for development of the testis (Box 1). A particularly important gene in this regard is SOX9 (SRY related homeobox protein 9), which expresses a protein similar to SRY that incorporates HMG and is found in developing Sertoli cells. In the absence of SRY, SOX9 can still induce full male differentiation and its presence 
Box 1 Functions of genes implicated in sexual differentiation of the reproductive system

Capital letters are used for human genes and lower case for other species. The functions of the SF1 (sf1), WT1 (wt1), SRY (Sry), SOX (sox9) DAX1 (dax1), AMH (amh) and WNT4 (wnt4) genes are described in the text.

1. DMRT-1 (double sex and mab-3 related transcription factor 1)

Product: transcription factor

Function: important for proliferation of Sertoli cells and germ cells.

2. GATA 4 (Gata binding protein 4 gene)

Product: zinc-fingered transcription regulator

Function: activates AMH in concert with SF1

NB: both DMRT-1 and GATA4 are expressed in the gonads of both sexes in early development. Expression remains high in the testis throughout pregnancy, but at mid-pregnancy they are down-regulated in the ovary suggesting a role in sexual dimorphism of the gonads.

3. Hox family genes, e.g. KIMI, LHX9, EMX2 and M33 (Homeobox containing transcription factor genes). Product: transcription factors

Functions: all the genes are required for development of the genital ridge and the gonads. LHX9 is required for full expression of SF1 and M33 is a mediator or co-operative factor for SRY to activate SOX9.

4. Fog 2 (friend of Gata)

Product: unknown

Function: Fog 2 and Gata 4 are essential for expression of Sox9 and AMH. In fog 2 knock-out mice, there is also a decreased expression of Sry. Fog 2 is not required for sf1 or wt1 expression.

5. POD1

Product: unknown

Function: POD1 is necessary for normal vascularisation of the testis and it is also necessary for gonadal development in both sexes, because the Pod1 knock-out mouse exhibits gonadal hypoplasia.

6. Vnn 9

Product: Vanin-1 (vascular non-inflammatory module-1)

Function: Vanin-1 is a cell surface protein regulating integrin-mediated cell adhesion and involved in cell migration, in particular Sertoli cell association with peri-tubular myoid cells. Vanin 1 may activate SOX 9 expression.

7. FGF-9 (Fgf9)

(fibroblast growth factor 9)

Product: protein signalling molecule

Function: fgf- 9 is expressed in Sertoli cells and is necessary for their proliferation. It is essential for testis formation as the fgf- 9 knock-out mouse exhibits a female phenotype at birth.

References

Koopman (2001), Chan \& Rennert (2002), Fleming \& Vilain (2004), Park \& Jameson (2005).

is essential for normal development (Koopman et al. 2001). Another HMG protein, SOX8, acts similarly to SOX9, but is not essential for normal development (Koopman 2005). An example of one of the genes activated by SRY is the intragonadal regulator fibroblast growth factor (FGF) 9, part of a large family of signalling molecules. The effects of fgf9 deletion in mice indicates its importance in the proliferation and differentiation of Sertoli cells, which in turn are important in initiating spermatic cord formation and increasing Leydig cell and perituberal myoid cell numbers (Chan \& Rennert 2002). In contrast to suggesting that SRY stimulates genes necessary for development of the testis, an alternative 'disinhibition' theory has been proposed that states that SRY encodes a repressor agent, which inhibits an inhibitory ' $Z$ ' factor (see Park \& Jameson 2005 and Box 2).

DAX1 (dosage-sensitive sex-reversal, adrenal hyperplasia congenital $X$ chromosome 1 ) is situated on the $X$ chromosome and is upregulated by WT1 and SF1. DAX1 regulates testis development in a dose- and timesensitive way (Vilain \& McCabe 1998, Fleming \& Vilain 2004). It is essential for early testicular development, because in its absence, Sertoli cells do not develop and spermatogenesis is impaired and DAX 1 is also necessary for Leydig cell proliferation and differentiation (see Sharpe 2006). However, its over-expression, e.g. when the gene is duplicated, interferes with testis development, because it encodes for a transcriptional repressor that suppresses SRY, SFI and SOX9 in a dose-dependent 
Box 2 SRY as a suppressor of a masculinizing inhibitory factor

SRY is a homologue of the $\mathrm{X}$ chromosome gene, SOX3 and sequence comparisons between species suggest that SRY is a degraded relic of SOX3. SRY appears to have opposite, or, at least, different actions to SOX3 and some authors suggest that rather than 'switching on' testis differentiating genes, SRY represses a testis inhibitor, designated the ' $Z$ ' factor. This inhibitor suppresses pro-testis events acting on both $X X$ and $X Y$ backgrounds upstream to SRY. Loss or mutation of the ' $Z$ ' factor could result in a XX male and increased ' $Z$ ' factor activity could cause a sex reversal (XY female) if it was high enough to overcome SRY suppression. Wnt 4 and DAX1 are possible candidates for the ' $Z$ ' factor since both prevent testis formation.

\section{References}

Vilain \& McCabe (1998), Marshall Graves (2000), Bowles \& Koopman (2001), Koopman (2001).

manner (Vilain \& McCabe 1998, Park \& Jameson 2005). DAX1 is present in both sexes until mid-pregnancy (embryonic day (E) 12.5 in mice), after which it is only expressed in the female and may be important for ovarian development or rather protection against testis formation in the female (Vilain \& McCabe 1998). The possible sites of action and interactions of some of the genes regulating development of the male reproductive system are illustrated in Fig. 1.

\section{Hormonal sex}

The gonadal ridge in the $\mathrm{XY}$ embryo differentiates into the testis from E12 in the rat (Viger et al. 2005), by forming the testicular cords (enclosing the germ cells and Sertoli cells), followed by differentiation of the Leydig cells and finally rounding of the testis (Byskov 1986). This last event is important for minimizing the feminizing influence of the adjacent mesonephric tissue, which may inhibit testicular cord formation, reduce steroidogenesis in Leydig cells and stimulate germ cell meiosis at an inappropriately early stage in foetal life (germ cell meiosis normally begins at puberty in males; Byskov 1986). Activin produced by the foetal testis may play a role in reducing germ cell proliferation and reducing any influence of mesonephric tissue-derived feminizing agents, because it inhibits germ cell and mesonephron cell DNA synthesis (Kaipia et al. 1994). The earliest marker of testis formation is the expression of AMH in Sertoli cells (E12.5 in mice and 6 weeks of pregnancy in humans). This expression of $\mathrm{AMH}$ is primarily induced by SOX9, together with WT1, SF-1 and GATA4 and it acts to cause regression of the Mullerian tract over the critical period of E16-20 in rats and 8-9 weeks of pregnancy in humans (Viger et al. 2005). The effects of AMH are mediated by $\mathrm{AMH}$ type II receptors, which are only present during the critical period and thus, although AMH continues to be secreted until birth, its activity ceases after AMH type II receptor expression stops at the end of the critical period (Rey et al. 2003).

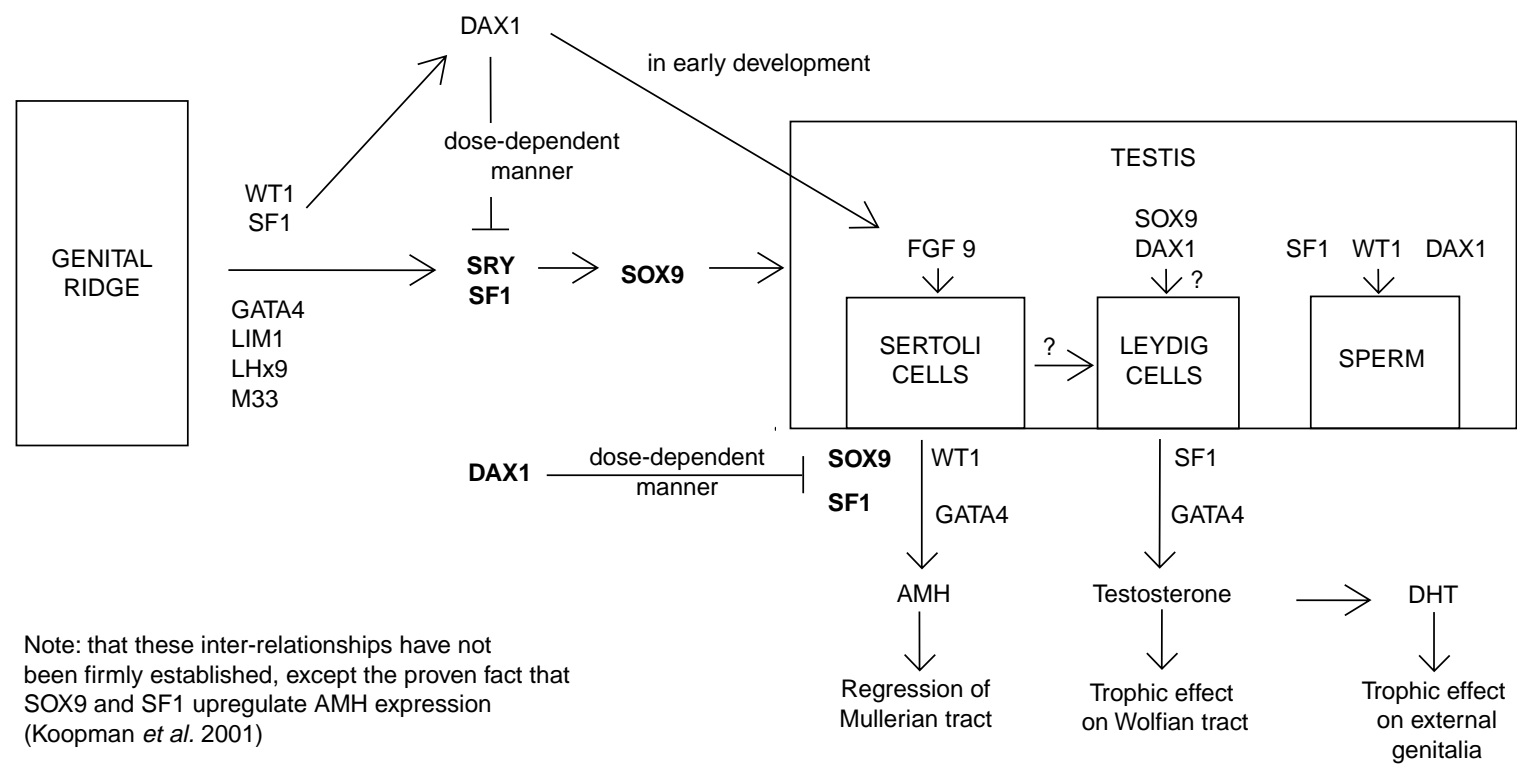

Figure 1 Genetic regulation of the male reproductive system (modified from Koopman 2001). 
The testis synthesize testosterone in Leydig cells from E15 in the rat (El-Gehani et al. 1998a) and 12-17 weeks of pregnancy in humans (Diez d'Aux \& Pearson Murphy 1974). Low levels of testosterone are synthesized by Leydig cells in the foetal rat testis on E15 and its intratesticular concentration rises slowly over E16-17. Testicular testosterone levels then rise sharply on E18, to peak at E19 and then decline over E20-21 (Bentvelsen et al. 1995). Circulating levels of testosterone are first detectable on E16 or 17, peak at E18 and fall on E20 (Weisz \& Ward 1980, Ward et al. 2003), followed by a second surge on the day of birth (Rhoda et al. 1984). Androgen receptor immunoreactivity (AR-ir) first appears in the rat urogenital tract on E14, with equal densities in males and females (Bentvelsen et al. 1995). Testicular androgens increase AR density in males over the ensuing prenatal period, resulting in a greater expression in males compared with females (Bentvelsen et al. 1995).

Leydig cells in the foetal testis are morphologically and functionally different from those in the adult (Huhtaniemi \& Pelliniemi 1992). In foetal Leydig cells, the initiation of testosterone synthesis is independent of LH secretion, because LH only becomes detectable in the pituitary on E16 and in the plasma on E17. LH does not become functionally steroidogenic until E20, which is well after the appearance of testosterone on E15 and its surge on E18 (El-Gehani et al. 1998a). The early independence of testosterone secretion from gonadotrophin activity is supported by the fact that genetic mutant or knock-out male mice deficient in gonadotrophin-releasing hormone, luteinizing hormone $(\mathrm{LH})$ or $\mathrm{LH}$ receptors, all exhibit normal prenatal masculinization (El-Gehani et al. 2000, Zhang et al. 2001). Possible alternative initiators of foetal testosterone secretion are pituitary adenylate cyclase-stimulating polypeptide (El-Gehani et al. 2000), vasoactive intestinal peptide (El-Gehani et al. 1998b) and the natriuretic peptide hormones (El-Gehani et al. 2001). These peptides and their receptors are all present around E15 in the rat and are all steroidogenic.

The synthesis of testosterone from cholesterol involves trafficking between mitochondria and smooth endoplasmic reticulum, mainly via $\mathrm{P}_{450}$ haem-containing enzymes. The genes coding for these enzymes are abbreviated to CYP and are upregulated by SF1 and GATA4. The principal enzymes involved in the production of testosterone are cytochrome P450 side-chain cleavage enzyme, the $3 \beta$-hydroxysteroid dehydrogenases, types $1-6$, the $17 \beta$ hydroxylase $17-20$ lyase enzyme and the 17 hydroxysteroid reductases, types 1-3 (Stocco \& McPhaul 2006); further details are given in Box 3.

Testosterone is essential for the morphological differentiation of the male reproductive tract. It acts in an exocrine manner, diffusing down a gradient from the testis via efferent ductules to the lumen of the Wolfian tract. Thus, masculinization occurs sequentially; first the efferent ductules, then the Wolfian tract followed by

Box 3 Testosterone synthesis

There are two possible pathways for testosterone synthesis:

The $\Delta 4$ pathway utilised in most rodent species: Cholesterol $\rightarrow$ Pregnenolone $\rightarrow$ Progesterone $\rightarrow$ Androstenedione $\rightarrow$ Testosterone

The $\Delta 5$ pathway utilised in humans and higher primates: Cholesterol $\rightarrow$ Pregnenolone $\rightarrow 17$-hydroxypregnenolone $\rightarrow$ Dehydroepiandrosterone $\rightarrow$ Androstenedione $\rightarrow$ Testosterone

The enzymes required for these conversions are:

1. Cytochrome P450 side-chain cleavage enzyme (P450 sCC; CYP 11A1)

This converts cholesterol to pregnenolone

2. $\beta$-Hydroxysteroid dehydrogenase/ $\Delta 4-\Delta 5$ isomerase $(3 \beta-H S D)$

This catalyses the conversion of pregnenolone to progesterone i.e. it converts $\Delta 5$-3 $\beta$-hydroxysteroids to $\Delta 4$-3-ketosteroids. $3 \beta$-HSD exists as 2 isoforms in the human and it is type II that is involved in testosterone synthesis. In the rat, there are 4 isoforms and type la is the major form involved in the synthesis of testosterone in the rat. 3. Cytochrome P450 17 $\alpha$-hydroxylase17-20 lyase enzyme (P450c17; CYP 17)

This catalyses the $17 \alpha$ hydroxylation of C21 steroids followed by cleavage of the C17-C20 bond of C21 steroids resulting in the conversion of pregnenolone to the C19 steroid, Dehydroepiandrosterone ( $\Delta 5$ pathway) or the C21 steroid, progesterone to the $\mathrm{C} 19$ steroid, androstenedione ( $\Delta 4$ pathway).

4. $17 \beta-H y d r o x y s t e r o i d ~ d e h y d r o g e n a s e(17 \beta-H S D)$

This reversibly converts androstenedione to testosterone. There are three isoforms, type three being the only one found in the testis. 
the upper part of the epididymis and finally the remaining epididymis, vas deferens and seminal vesicles (Bentvelsen et al. 1995). While testicular development is initially independent of steroids, the later proliferation of Sertoli cells requires testosterone (Sharpe 2006). Testosterone is also converted to the tenfold more potent androgen, dihydrotestosterone (DHT; by $5 \alpha$-reductase type II), which, in turn, is essential for development of the male urethra, prostate gland, penis and scrotum, together with the growth of tissue between the anus and the genital orifice. The greater ano-genital distance in the male is widely used as a morphological marker for differentiating the sex of neonatal rodents. SF1 induces expression of insulin-like factor 3 (INSL3) in Leydig cells, which is essential for the development of the gubernaculum and the early (intra-abdominal) stage of testicular descent. The later (inguino-scrotal) stage of testicular descent is dependent upon testosterone (Viger et al. 2005, Sharpe 2006).

\section{Development of the female reproductive system}

\section{Genetic sex}

The development of the female reproductive tract has received much less attention than the male tract, probably because of the widespread perception that it occurs 'by default'. The equivalents of the SRY and SOX9 transcription factors have not been demonstrated in the female. However, repressor proteins preventing male differentiation are expressed in the ovary, e.g. the DAX1 gene product, which suppresses SF1 and SOX 9 activity. Another example is WNT 4 (a member of the Wnt/Winglass family), which in common with DAX1 is expressed solely in the ovary after mid-pregnancy, where it maintains oocyte numbers. In earlier pregnancy, WNT 4 suppresses Leydig cell differentiation and the synthesis of testosterone, perhaps by repressing SF1 function or inhibiting migration of steroidogenic precursor cells into the developing ovary (Fleming \& Vilain 2004). WNT 4 is a candidate for the ' $Z$ ' factor (see Box 2), because female Wnt 4-null mice develop virilised gonads and Wolfian derivatives (see Park \& Jameson 2005). Normally, Wnt 4 is down-regulated in males, thus removing any potential inhibition of SF1 function (Park \& Jameson 2005).

In the female, FOXL 2 and FIG $X$ are transcription factors that control the development of granulosa cells and oocytes within the ovary (Loffler \& Koopman 2002, Fleming \& Vilain 2004). In the absence of androgens and $\mathrm{AMH}$, the Wolfian Tract regresses and the Mullerian tract develops into the uterus, cervix and upper vagina. DAX1 plays a role in the development of the female reproductive tract in that it inhibits $\mathrm{AMH}$ expression (presumably by suppressing SRY, WT1 and SF1) and WNT 4 is part of a cascade of genes controlling the development of the Mullerian tract into the oviducts, uterus, cervix and vagina (Rey et al. 2003). Animal studies have demonstrated that Wnt 4 is regulated by Wnt 7a and in turn, Wnt 4 stimulates a family of Hox a and Hox d genes. The whole pathway is down-regulated in the absence of Wnt 7a, leading to abnormalities in the development of the rostro-caudal axis of the female reproductive tract, i.e. uterine morphology develops in the oviduct, vaginal morphology develops in the uterus, the cervix and vagina fail to fuse in the midline and remnants of the Wolfian tract remain. Oestrogen downregulates Wnt 7a and also Hox a10 at the other end of the cascade and it is likely that the abnormalities in the reproductive tract of female offspring of women treated prenatally with the synthetic oestrogen, diethylstilboestrol, are due to the oestrogenic effects of this potent drug (Kitajewski \& Sassoon 2000).

\section{Hormonal sex}

In the early stages of ovarian development, the germ cell precursors (gonocytes) rapidly proliferate by mitotic division over E14-15 and this proliferation is closely followed by meiotic division, which, in contrast to the male, occurs during foetal life and is considered to be one of the first stages of ovarian differentiation (Hilsher et al. 1974). The earliest meiotic divisions occur in the germ cells close to the mesonephric connections in the central area of the ovary and it has been suggested that the mesonephros secretes a meiosis-inducing substance (Byskov 1986). This substance may be the same as the meiosis-activating sterols produced in adult gonads that are intermediaries in the cholesterol biosynthesis pathway (Byskov et al. 1998, Rozman 2000). The foetal production of the meiosis-inducing substance is not sexually differentiated, but in the male, germ cells are protected from its action by their enclosure within the testicular cords, whereas in the female, germ cells are exposed to its influence (Byskov 1986).

Activin may be involved in the regulation of germ cell division and mesonephron activity in both males and females. The activin $\beta_{B}$ subunit and activin receptor type IIB mRNA are expressed in the gonads and mesonephroi of both sexes over E14-15 (Roberts et al. 1991, Kaipia et al. 1994). Therefore, activin and its receptors are probably present at the relevant time for female germ cell division. Experiments employing exogenous recombinant activin-A have revealed that activin stimulates DNA synthesis in the gonads and mesonephroi in a sexually differentiated manner. In males, activin inhibits DNA synthesis (see section: Development of the male reproductive system; Hormonal sex), whilst in females, it stimulates DNA synthesis, particularly over E14-15 (the time of rapid germ cell division), but activin becomes ineffective on E18 when meiosis ceases. It is therefore possible that activin stimulates division of female germ cells and also enhances the production of the meiosis-inducing substance from the mesonephron (Kaipia et al. 1994). Although follistatin has effects on 
adult gonads and is present in the foetal and neonatal ovary, its role in development has not been clarified (Kaipia et al. 1994).

\section{Effects of environmental endocrine agents on sexual differentiation of the reproductive system}

Compounds that can mimic or antagonise the effects of oestrogen and/or androgen are collectively referred to as endocrine disruptors (EDs). The oestrogenic agents comprise xenoestrogens, which are non-steroidal synthetic compounds used in industry and agriculture, and phytoestrogens, which are non-steroidal compounds that occur naturally in plants and fungi (see Safe 2005 and Box 4 for selected EDs and their actions in rodents). EDs can be ingested in the diet or inhaled from the atmosphere, and there are currently about 60 chemicals that have been identified and characterized as EDs (Brevini et al. 2005, Safe 2005).

The disastrous effects of treating pregnant women with the potent non-steroidal synthetic oestrogenic compound, diethylstilboestrol, on reproductive tract development in both male and female offspring leading to testicular or vaginal cancer in adulthood, first highlighted the effects of exogenous endocrine agents on foetal development (see Bay et al. 2006). This, together with the increased prevalence of male reproductive disorders over recent years, has led to the hypothesis that environmental EDs can cause abnormal sexual differentiation of the reproductive tract and brain, and malfunction of the adult reproductive system (Colborn et al. 1993).

There are four principal disorders of the reproductive system in males: cryptorchidism (failure of testicular descent), hypospadias (ventral opening of the urethra on the penis), low sperm count (there has been a $40 \%$ decrease in sperm count in the last 50 years according to meta-analysis of 61 Scandinavian and Northern European studies (Carlsen et al. 1992)) and testicular cancer in adulthood. Together, these four disorders are referred to as testicular dysgenesis syndrome (TDS) or developmental oestrogenic male phenotype (Safe 2005, Bay et al. 2006, Sharpe 2006). Although the association between EDs and TDS has been taken seriously by regulatory bodies, whether the association is causal or not is still a matter of debate, because the expression of some aspects of TDS does not vary with changes in exposure to EDs and there are marked demographic differences in the prevalence of TDS that cannot be explained by differences in exposure to EDs. For example, there is four times more cryptorchidism and testicular cancer in Denmark than in Finland, despite similar exposure to an ED (in this case organochloride pesticides; Safe 2005). In a critical survey of studies of the reproductive health of offspring of parents exposed to EDs, Vidaeff \& Sever (2005) concluded that there was not a strong correlation, but sufficient to warrant further investigation.

The evidence for an association between environmental EDs and impaired sexual differentiation and development is much stronger for wildlife than it is for humans. A wide variety of EDs have been implicated in the feminization of male birds, alligators and fish (see Hoyer 2001). Moreover, laboratory studies have replicated the effects of EDs on the development of the male rodent reproductive system that have been observed in humans. For example, administration of phthalates (which reduce testosterone synthesis) to a pregnant dam produces TDS in male offspring, similar to that observed in humans (Sharpe 2006). This has led to the suggestion that TDS is caused by low-testosterone activity over the critical period for development of the testis and differentiation of the Wolfian tract (Sharpe 2006). Once the testis have been formed from the gonadal ridge, they produce testosterone, which normally has a positive feedback effect on further testicular development. Failure of this feedback results in disordered testicular structure, abnormal sperm production and reduced testosterone synthesis. Exogenous oestrogenic agents (e.g. diethylstilboestrol or alkyl phenols) could induce these abnormalities by: (a) impairing Leydig cell development, (b) exerting a negative feedback effect on the folliclestimulating hormone ( $\mathrm{FSH}$ ) release necessary for normal Sertoli cell development, (c) inactivation of steroidogenic enzymes or (d) inhibiting expression of androgen receptors (AR). Anti-androgen agents would be expected to have similar effects by inhibiting testosterone synthesis (e.g. by phthalates) or activity (e.g. by polychlorinated biphenyls; Vidaeff \& Sever 2005, Sharpe 2006).

Most EDs exert weak endocrine activity, but their relatively potent biological effects can be explained by the fact that they have a low affinity for serum steroidbinding proteins and therefore, their biologically active concentration is proportionately higher than that of similar amounts of endogenous hormones that have a higher affinity for serum steroid binding proteins (Vidaeff \& Sever 2005). Many EDs are also lipophilic and so bioaccumulate in fat deposits, giving rise to high body concentrations that can be released over a long period of time. EDs can enhance the activity of endogenous steroids by preventing their catabolism by enzymes such as sulphotransferase. Many EDs exhibit U-shaped dose-response curves, so that they are most potent at low concentrations. It is also possible that weak EDs may have relatively greater effects on the undeveloped foetus compared with the adult. Finally, some EDs have a wide profile of activity, e.g. bisphenyl $A$ is an oestrogen agonist and a potent androgen antagonist, and alkyl phenols are weak oestrogen agonists and potent antiprogestagens. Both types of compound can also act as agonists or antagonists depending on their absolute concentration or their concentration relative to endogenous steroids. All of these factors could play a 
Box 4 Actions of some endocrine disruptors on rodents

Effect of prenatal administration on:

\begin{tabular}{|c|c|c|}
\hline Chemical group & Use or source & Mechanism of action \\
\hline & & \\
\hline $\begin{array}{l}\text { 1. Alkyl Phenols e.g. } \\
\text { 4-ocytlphenol, 4-nonyl- } \\
\text { phenol }\end{array}$ & $\begin{array}{l}\text { Surfactants used in her- } \\
\text { bicides, paints, deter- } \\
\text { gents, paper, textiles }\end{array}$ & $\begin{array}{l}\text { Binding to ERs. Also } \\
\text { weak androgenic } \\
\text { activity }\end{array}$ \\
\hline
\end{tabular}

Males Females References

2. Isoflavones e.g. Plant origin e.g. soy coumestrol, genistein, beans, alfalfa, clover diadzein

3. Bisphenol-A

Used in production of plastic lined containers, dental sealants and epoxy resins
4. Diethylstilboestrol Potent non-steroidal synthetic oestrogen. Used in humans over 1940-1970s to prevent spontaneous abortion

\section{Anti-Androgenic Agents}

1. Polychlorinated Pesticides biphenyls (PCBs) $\mathrm{pp}^{\prime}$ DDT (and its metabolite ppDDE), methoxychlor, arochlor, kepone

2. Phthalates $(P)$ di-n-butylP (DBP) di-2-ethylhexylP, butylbenzyl $\mathrm{P}$, di-isononyl $\mathrm{P}$ paper
Binds to ERs

Used in adhesives, aerosols, coating on receptors
Binding to ERs. Also potent anti-androgen

Binding to ERs with greater affinity for $E R \beta$
1. Reduction in testosterone synthesizing and metabolising enzymes 2. Small testis 3. Abnormal sperm n.b. Increased sexual arousal (unexpected) Feminization as indicated by:

(a) reduced AGD

(b) reduced aggressive

behaviour

(c) reduced male sexua behaviour

Feminized as indicated by:

(a) reduced sexual arousal

(b) reduced aggressive behaviour

(c) reduced anxiety

(d) increased locomotion

(e) enlarged LC n.b. Sexual orientation normal

1. Abnormal reproductive tract development (see legend) with retention of Mullerian tract. Infertility in $60 \%$ of treated mice

2. Feminization as indicated by:

(a) reduced $A G D$

(b) increased loco-

motion

(c) enlarged LC

Binds to ARs as antagonists and also to aryl hydrocarbon

Prevents androgen synthesis by down-regulating genes required for steroidogenesis
1. Abnormal reproductive tract development and abnormal spermatogenesis

2. Feminization as indicated by:

(a) reduced $A G D$

(b) Reduced numbers of

PRs in CNS

1. Abnormal reproduc-

tive tract development

2. Reduced testis size

3. Reduced sperm

counts

4. Feminization as indi-

cated by:

(a) reduced AGD

(b) retention of nipple

structures

$-$

Masculinization as indicated by:

(a) constant oestrus

(b) reduced positive

feedback response to

steroids

(c) masculinized-sexual

orientation

Masculinization as

indicated by:

(a) constant oestrus

(b) lack of corpora lutea

(c) enlarged SDN-POA

(d) reduced female sexual behaviour

Masculinization as indicated by:

(a) constant oestrus (b) a greater number of mature follicles and fewer corpora lutea

(c) reduced LC

(d) masculinization of non-social behaviours (anxiety, locomotion, exploration) (e) increased prepubertal play n.b. Female sexual behaviour increased (unexpected) 1. Abnormal reproductive tract development

(see legend) with reten- Kitajewski \& Sassoon

tion of the Wolfian Tract (2000), Yamamoto et al. 2. Masculinization as (2005) indicated by:

(a) constant oestrus

(b) reduced LC

(c) increased male sexual behaviour

Masculinization as indicated by:

(a) constant oestrus

(b) reduced corpora

Hoyer (2001),

Masutomi et al. (2003),

Takagi et al. (2005),

Gray et al. (2006)

lutea numbers

(c) increased numbers

of PRs in CNS$$
\text { of PRs in CNS }
$$

Pocock et al. (2002)

(2005), Aydogan \&

lini et al. (1999,

(2003), Markey et al. (2003)

Greco et al. (1993),

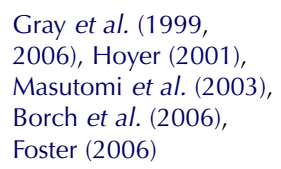

Gray et al. (1999,

2006), Hoyer (2001),

Masutomi et al. (2003),

Borch et al. (2006),

Foster (2006) 


\begin{tabular}{|c|c|c|c|c|c|}
\hline \multicolumn{6}{|l|}{ Continued. } \\
\hline \multirow[b]{2}{*}{ Chemical group } & \multirow[b]{2}{*}{ Use or source } & \multirow[b]{2}{*}{ Mechanism of action } & \multicolumn{3}{|c|}{ Effect of prenatal administration on: } \\
\hline & & & Males & Females & References \\
\hline $\begin{array}{l}\text { 3. Polycyclic } \\
\text { aromatic hydrocarbons } \\
\text { or Dioxins e.g. 2, 3, 7, } 8 \\
\text { tetrachloride benzo-p- } \\
\text { dioxin, polychlorinated } \\
\text { dibenzodioxins }\end{array}$ & $\begin{array}{l}\text { Ubiquitous environ- } \\
\text { mental contaminant } \\
\text { resistant to degradation } \\
\text { and metabolism. Lipo- } \\
\text { philic in nature and so } \\
\text { accumulates in the food } \\
\text { chain and tobacco. }\end{array}$ & $\begin{array}{l}\text { Anti-oestrogen and } \\
\text { anti-androgen activity. } \\
\text { One of the most } \\
\text { important ligands for } \\
\text { the aryl hydrocarbon } \\
\text { receptors, which } \\
\text { interfere with ER bind- } \\
\text { ing to DNA response } \\
\text { elements and also } \\
\text { antagonise testosterone } \\
\text { activity }\end{array}$ & $\begin{array}{l}\text { 1. Reduced testis size } \\
\text { and sperm count in } \\
\text { humans }\end{array}$ & $\begin{array}{l}\text { Masculinises the } \\
\text { laterality of the } \\
\text { cortical hemispheres }\end{array}$ & $\begin{array}{l}\text { Hoyer (2001), Zareba } \\
\text { et al. (2002), Sharpe } \\
\text { (2006) }\end{array}$ \\
\hline $\begin{array}{l}\text { 4. Dicarboximide } \\
\text { e.g. vinclozolin }\end{array}$ & Fungicide & $\begin{array}{l}\text { Binds to ARs as an } \\
\text { antagonist }\end{array}$ & $\begin{array}{l}\text { 1. Abnormal reproduc- } \\
\text { tive tract development } \\
2 \text {. Reduced sperm } \\
\text { count. Feminization as } \\
\text { indicated by: } \\
\text { (a) reduced AGD } \\
\text { (b) retention of nipple } \\
\text { structures }\end{array}$ & & $\begin{array}{l}\text { Kitajewski \& Sassoon } \\
(2000), \text { Foster (2006), } \\
\text { Gray et al. (2006) }\end{array}$ \\
\hline \multicolumn{6}{|c|}{$\begin{array}{l}\text { Abbreviations: AGD, ano-genital distance (longer in males); AR, androgen receptor; ER, oestrogen receptor; LC, locus coeruleus (smaller in } \\
\text { males); PR, progesterone receptors (density higher in male brain); SDN-POA, sexually dimorphic nucleus of the preoptic area (larger in males). } \\
\text { Abnormal reproductive tract development in females: with absence of oviducts or malformation of oviducts with uterine-like epithelium vaginal- } \\
\text { like epithelium in the uterus with lack of glandular cells. Cellular disorganization of the uterine myometrium. Midline of the cervix and vagina not } \\
\text { fused. Abnormal reproductive tract development in males: fibrotic, intra-abdominal testis. Absence or abnormalities of accessory sex glands } \\
\text { (epididymus, seminal vesicles, ventral prostate). Constant oestrus: indicates lack of cyclical release of gonadotrophins (normal female pattern) } \\
\text { resulting in acyclicity, anovulation, persistant antral follicles and lack of corpora lutea. }\end{array}$} \\
\hline
\end{tabular}

part in the way, in which EDs cause disruption of normal sexual differentiation (Brevini et al. 2005, Vidaeff \& Sever 2005).

\section{Sexual differentiation of the brain}

\section{Introduction}

The classic dogma concerning sexual differentiation of mammalian non-reproductive tissues is that chromosomal sex determines formation of the gonads, and that gonadal hormones in turn control the phenotype of non-gonadal tissues, including the brain. Thus, until recently, genetic factors were considered to be restricted to the expression of genes regulating gonadal hormones. The importance of the influence of sex steroids on brain sexual differentiation was first shown by experiments analogous to those of Jost et al. (1973) in which removal of the testis (and thus the source of testosterone) early in neonatal life resulted in feminization of brain-regulated functions and behaviour in adulthood, whilst administration of exogenous testosterone to the neonatal female induced masculinization (Pfeiffer 1936, Phoenix et al. 1959). The results of these experiments appeared to negate the necessity for a direct genetic effect on sexual differentiation of non-gonadal tissues and because it is easier to experimentally manipulate hormonal influences than to alter gene expression, much more has been discovered about the hormonal than genetic control of brain sexual differentiation. However, several reports have indicated that sexual differentiation of the embryonic central nervous system (CNS) occurs before the onset of the release of prenatal/neonatal gonadal hormones. Furthermore, recent experiments have demonstrated that neural expression of $X$ and $Y$ genes can contribute to sex differences in brain function, independent of the action of gonadal steroids. It has been suggested that early events in sexual differentiation, e.g. cell migration, are initially solely dependent on genetic influences, but then become subject to the control of gonadal steroids as they and their receptors become available; hence the apparent dominance of gonadal steroid influences in most known instances of sexual differentiation (see Tobet 2002).

\section{Genetic control of sexual differentiation of the brain}

Genetically controlled brain functions and sexual dimorphism (hormone independent)

One of the earliest observations of genetic-dependent and hormone independent sex differences in brain tissue was reported by Reisert and colleagues (see Reisert \& Pilgrim, 1991) working on diencephalon and mesencephalon cell cultures taken from E14 (endogenous gonadal testosterone is not secreted until E16 or 17) male and female rat foetuses. These authors observed that mesencephalic cultures from female rats contained more tyrosine hydroxylase (TH)-immunoreactive (ir) neurones (TH is a marker of the presence of dopamine; DA) than cultures from males. However, in males 
mesencephalic DA neurones were more mature than in females as indicated by increased $\left[\mathrm{H}^{3}\right]$ DA uptake. In the diencephalon cultures, although the number of $\mathrm{TH}$-ir neurones was not sexually differentiated, neurones from females were more mature than those from males and contained higher concentrations of DA and their TH exhibited a greater activity as assessed by the accumulation of dihydroxyphenylalanine in the presence of an aromatic amino-acid decarboxylase inhibitor. These sex differences were not affected by the manipulation of sex steroid activity (by administration of oestradiol or androgen antagonists), either in vivo before foetuses were removed from the uterus, or to cell cultures in vitro.

Deletion of the Sry gene from male mice $\left(\mathrm{XY}^{-}\right)$results in a female phenotype. When a Sry transgene is inserted into an autosome of these mice, $\mathrm{XY}^{-}$Sry mice are created, which possess testis and are fertile males. Mating $X Y^{-}$Sry with normal $X X$ females produces four types of progeny: $X X$ and $X Y$ mice without the Sry gene that bear ovaries (females) and $X X$ and $X Y$ mice with the Sry gene that possess testis (males; Arnold et al. 2004). Comparison of these mice allows assessment of sex chromosome effects independent of gonadal sex on sexually differentiated structures and functions. Cell cultures from E14 mesencephalon revealed that XY mice with or without Sry contained significantly more TH-ir neurones than XX males, XX-Sry males and normal (XX) females (Carruth et al. 2002). These findings conflict with those of Reisert \& Pilgrim (1991), who reported a greater number of TH-ir neurones in XX compared with $X Y$ mesencephalic cultures at E14 and suggest that cells from genetically manipulated animals may not necessarily be similar to those from natural XX and XY animals. Studies of adult mouse substantia nigra have revealed that there are more $\mathrm{TH}$-ir cells (i.e. DA neurones) in males $(X Y)$ than females $(X X)$ and that the expression of TH-ir is regulated by Sry and is independent of gonadal hormones. This regulatory effect is indicated by the fact that Sry mRNA is present in $10 \%$ of TH-ir cells in the substantia nigra and administration of Sry antisense oligodeoxynucleotides into the substantia nigra reduces $\mathrm{TH}$ expression (Dewing et al. 2006). These results support those of Carruth et al. (2002) on mesencephalic cell cultures, but are in conflict with those of Reisert \& Pilgrim (1991). In the diencephalon, the density of DA neurones in the anteroventricular paraventricular nucleus (AVPV) of the hypothalamus is greater in female than in male mice (Simerly et al. 1985b). This sexual differentiation may have been masked in the studies of Reisert \& Pilgrim (1991), who investigated the hypothalamus as a whole and did not find any sex difference in the density of DA neurones. The sex difference in the density of DA neurones in the AVPV is dependent on neonatal steroids and not the presence of Sry (Simerly et al. 1997, De Vries et al. 2002). Sexual differentiation of male sexual behaviour, social exploration, the size of the spinal nucleus of the bulbocavernosus and the density of hypothalamic progesterone receptors (PRs) have also been studied in XX and XY mice, with and without the Sry gene. The sex differences in all of these parameters were found to be dependent upon gonadal and not chromosomal sex (De Vries et al. 2002, Wagner et al. 2004). However, vasopressin-ir fibre density in the lateral septum (which is normally higher in males) was greater in XY-Sry males compared with XX-Sry males and similarly vasopressin-ir in $X Y^{-}$females was greater than in XX females (De Vries et al. 2002), indicating that this parameter is dependent on chromosomal and independent of gonadal sex. Moreover, comparing the 'sexes' in C57/B4/6JE $\mathrm{i}-\mathrm{Y}^{\mathrm{POS}}$ mice that produce sex-reversed $\mathrm{XY}$ females, revealed that the $X Y$ females exhibit a more male-like spatial perception ability compared with $X X$ females, whilst their performance in other tests of cognitive ability did not differ (Stavnezer et al. 2000).

To date, there has been little investigation of the interaction between genetic and hormonal influences of sexual differentiation, although there is evidence on genetically controlled differences in response to steroid action. In a study of nine different strains of rats, variations in brain structure (i.e. in the sexually dimorphic nucleus of the preoptic area; SDN-POA), aromatase activity, plasma gonadotrophin concentration and male sexual behaviour have been observed, particularly in Wistar $(\mathrm{WF} / \mathrm{NGu})$ and Noble $(\mathrm{NB} / \mathrm{Gr})$ rats, but there was no significant difference in plasma oestradiol or testosterone levels (Lephart et al. 2001). The authors suggested that these phenotypic variations may be due to differences in the response to steroids, which are controlled by quantitative trait loci, i.e. differences in expression of specific genes (Lephart et al. 2001).

In summary, sex differences in the density of TH-ir cells in the mesencephalon (Reisert \& Pilgrim 1991, Carruth et al. 2002, Dewing et al. 2006) and vasopressinir fibres in the lateral septum (De Vries et al. 2002), spatial perception ability (Stavnezer et al. 2000) and steroid sensitivity (Lephart et al. 2001) are controlled genetically, independent of gonadal hormones. It appears likely that further such examples of genetic control remain to be discovered.

\section{Identification of the genes controlling sexual differentiation of the brain}

$S R Y$ and $Z F Y$ genes are expressed in the human male hypothalamus and cortex (Mayer et al. 1998) and Sry, Sf1 and Dax 1 genes are expressed in the male mouse brain (Guo et al. 1995, Ikeda et al. 1996, Mayer et al. 2000). Thus, these genes are in a position to directly influence brain function. Sry has been shown to activate the P450 aromatase gene, which controls expression of the aromatase enzyme that causes conversion of testosterone to oestradiol within the brain (Loffler \& Koopman 2002). Sry also regulates expression of $\mathrm{TH}$-ir in the midbrain (Dewing et al. 2006). The Sf1 gene is required 
for neuronal migration into the ventromedial nucleus (VMN) of the hypothalamus. Furthermore, the distribution of cells expressing oestrogen receptors (ERs), galanin, neuropeptide $Y$ (NPY) and $\gamma$-aminobutyric acid (GABA) is altered in mice with a Sf1 deletion (Tobet 2002).

In an attempt to identify genes involved in sexual differentiation of the brain, microarrays and RT-PCR have been applied to brain tissue obtained from E10.5 mice, well before secretion of gonadal steroids begins on E16/17 (Dewing et al. 2003). Fifty candidate genes were found to exhibit male: female differences in expression. The expression of 36 of these genes was greater in females with that of one (the inactive $X$ specific transcript) being up to 18.5 fold higher than in males. The female: male expression ratio of the other 35 genes ranged from 1.2 to 2.4. Eighteen genes were more highly expressed in males than in females, including two located on the $\mathrm{Y}$ chromosome, with male: female expression ratios of 10 (DEAD box polypeptide) and 8.8 (eukaryotic translation initiation factor $2 ; \mathrm{Y}$ ) respectively (Dewing et al. 2003). Whilst the functions of these sexually differentiated genes are as yet unknown, the fact that they exist lays a foundation for further investigation into the genetic control of brain sexual differentiation and thence CNS function.

\section{Hormonal control of sexual differentiation of the brain}

\section{Steroid control of brain-regulated functions and} behaviour

Masculinization of the brain by steroids. Early experiments on rodents demonstrated that prenatal/neonatal exposure of females to testosterone masculinizes the pattern of gonadotrophin release and sexual behaviour in adulthood. Conversely, neonatal castration induces feminization of the same parameters in males. These findings indicate that not only is the peripheral reproductive system affected by foetal testosterone, but the hypothalamic-pituitary axis is also affected (Pfeiffer 1936, Phoenix et al. 1959, Barraclough 1966).

\section{i) Steroid action on behaviour}

Box 5 lists some sexual differentiated behaviours in rodents.

\section{ii) Steroid action on gonadotrophin release}

The feedback effect of steroids on gonadotrophin release can be inhibitory (negative feedback) or stimulatory (positive feedback). Both male and female rodents respond to the negative feedback effect of steroids, but only in female (and neonatally castrated male) rodents can steroids exert a positive feedback effect. This positive feedback leads to the typical female pattern of gonadotrophin release, with cyclical surges of LH and FSH (Fink et al. 1991, see Levine 1997). Male rats
Box 5 Sexually differentiated behaviours in rats

\begin{tabular}{|c|c|c|}
\hline Behaviour & $\begin{array}{l}\text { Sex showing } \\
\text { dominant } \\
\text { expression }\end{array}$ & Reference \\
\hline Male sexual behaviour & Male & Dorner et al. (1987) \\
\hline Female sexual behaviour & Female & Dorner et al. (1987) \\
\hline $\begin{array}{l}\text { Sexual orientation } \\
\text { toward a female }\end{array}$ & Male & Dorner et al. (1987) \\
\hline $\begin{array}{l}\text { Sexual orientation } \\
\text { toward a male }\end{array}$ & Female & Dorner et al. (1987) \\
\hline Locomotion & Female & Blizard \& Denef (1973) \\
\hline Exploration & Female & Joseph et al. (1978) \\
\hline Anxiety & Male & Archer (1975) \\
\hline Aggression & Male & $\begin{array}{l}\text { Beatty }(1979) \\
\text { Barfield (1984) }\end{array}$ \\
\hline Prepubertal social play & Male & Meaney et al. (1983) \\
\hline Feeding & Male & Nance \& Gorski (1975) \\
\hline Spatial Perception & Male & Stavnezer et al. (2000) \\
\hline
\end{tabular}

cannot respond to the positive feedback effect of steroids due to the prenatal testosterone surge (E16-19) and the later postnatal testosterone/oestradiol surge (Foecking et al. 2005) and so exhibit a tonic release of gonadotrophins (Loke et al. 1992). In contrast to the situation in rodents, there is no such sexual differentiation in primates (rhesus monkeys) and both gonadectomised males and females can respond to exogenous oestradiol priming with an $\mathrm{LH}$ surge and castrated males can even exhibit 28-day long ovarian cycles if provided with an ovarian transplant (Karsch et al. 1973, Norman \& Spies 1986). Steroids initially were considered to act predominantly at the level of the pituitary in primates (Nakai et al. 1978), but it has become clear that in both rats and monkeys of either sex, the negative and positive feedback effects of steroids are exerted at the level of both the hypothalamus and the pituitary. After suitable oestradiol priming, decreased LH release (negative feedback) results from a reduction in the amplitude of the pulsatile release of hypothalamic gonadotrophinreleasing hormone $(\mathrm{GnRH})$ in rats and primates and also a reduction in $\mathrm{GnRH}$ synthesis in rats. The site of the inhibitory action is the medial basal hypothalamus (especially the arcuate/median eminence; ARC/ME) in both rats and primates and it may also be exerted in the rostral POA, where the GnRH neurones are located in rats (Chappel et al. 1981, see Herbison 1998). At the same time, oestradiol desensitizes the pituitary towards the action of GnRH (Aiyer \& Fink 1974, Chappel et al. 1981). The positive feedback effects of steroids are also exerted at both the hypothalamus and pituitary, by increasing the $\mathrm{GnRH}$ pulse rate and sensitizing the pituitary's response to GnRH (Aiyer \& Fink 1974, Spies \& Norman 1975, Nakai et al. 1978, Levine et al. 1985). The main sites for the positive feedback effect of oestradiol are the POA and AVPV in the rat (Goodman 1978, Simerly 2002), but such a site has not been elucidated in primates, although it may be in the medial basal 
hypothalamus, where in contrast to rodents, GnRH neurones are known to be located (Silverman et al. 1994, Herbison 1998). There are sex differences in the degree of response towards steroids in both the rhesus monkey and rat; the female monkey and neonatally castrated male rat are both more sensitive to the negative feedback effect of oestradiol on $\mathrm{LH}$ release than the intact male (Petrusz \& Flerko 1965, Steiner et al. 1976) and when the steroid negative feedback effect is removed by gonadectomy, there is a more gradual rise in LH levels in females (Zanisi \& Martini 1975, Hood \& Schwartz 2000). However, the response of primates and rats towards the positive feedback effect of oestradiol differ. Male and androgenised female rhesus monkeys respond to the positive feedback effect of oestradiol with a larger LH surge than normal females (Steiner et al. 1976). On the other hand, oestradiol has a greater sensitising effect on the female rat pituitary response to $\mathrm{GnRH}$ compared with its effect on the male pituitary (Tang \& Tang 1979). Thus, adult female rats in vivo and their pituitaries in vitro are two to threefold more responsive to $\mathrm{GnRH}$ than males and neonatally androgenised females (Nakano et al. 1976, Fink \& Henderson 1977, Liaw \& Barraclough 1993).

\section{iii) Neonatal testosterone surge}

Testosterone synthesized by the foetal testis between E15 and birth is essential for masculinization of the reproductive tract as described in section: Development of the male reproductive system; Hormonal sex. Masculinization of the rodent brain is predominantly due to the surge in testosterone that peaks on E18 with a second surge on the day of birth (Weisz \& Ward 1980, Rhoda et al. 1984). A neonatal surge of testosterone also occurs in humans, starting 2 weeks after birth and peaking over the subsequent 2-4 months at the level normally present in adulthood. This then declines to a negligible level at 6 months of age that is maintained until puberty, when circulating testosterone concentration rises again (Forest et al. 1980). In neonatal females, testosterone levels remain approximately ten times lower than those in male neonates (Forest 1979) and even though $90 \%$ of circulating testosterone is bound, there is still an order of magnitude more free circulating testosterone in males than in females (Dixson et al. 1998).

There is no clear evidence that neonatal secretion of testosterone is involved in masculinization of the primate brain. However, it is known to be necessary for continued development of the penis and scrotum and may thus affect normal sexual activity. Suppression of neonatal testosterone in marmosets prevents normal development of the external genitalia and male sexual behaviour, but apparently not masculinization of the brain, because male sexual behaviour can be reinstated by exogenous testosterone in adulthood (Dixson et al.
1998). Thus, it appears that the mid-gestational (weeks 8-24) rather than the post-natal rise in testosterone induces masculinization of the primate brain. Although Swaab (2004) does not reject the possibility that the neonatal surge in testosterone has a masculinizing role in the human brain, he presents examples of genetic and hormonal defects that indicate mid-gestational exposure to testosterone is more important in regulation of sexual orientation and gender identity. Furthermore, CohenBendahan et al. (2005) provide evidence from primate studies that suggests that there may be multiple prenatal sensitive periods when different brain regions and thus behaviours are susceptible to hormonal modulation.

iv) The critical period for sensitivity to testosterone

The responses to the prenatal/neonatal testosterone surge in rats occur over function-specific and restricted time periods. Based on experiments in which neonatal testosterone was removed from males by castration on the day of birth, or was administered on specific days over the late gestation and neonatal period to females (or neonatally castrated males), it has been shown that in rats, testosterone-induced masculinization of sexual behaviour occurs from E18 up to a period between 15 and 30 days post partum (Bloch \& Mills 1995) and defeminization of sexual behaviour occurs from E18 up to day 7 post partum (Diaz et al. 1995, Rhees et al. 1997). Masculinization of the pattern of gonadotrophin release has been shown to occur from birth up to day 9 post partum and prenatal testosterone treatment (E18-22) has been reported to have no effect on the pattern of gonadotrophin release (Diaz et al. 1995, Rhees et al. 1997). However, a recent report suggests that prenatal testosterone treatment over E16-19 does masculinize the pattern of gonadotrophin release by preventing the normal ability of oestrogen to induce PRs, which in turn are essential for the induction of the preovulatory LH surge. The same prenatal testosterone treatment in females also masculinizes $\mathrm{LH}$ pulse frequency, which is normally greater in males (Foecking et al. 2005). Traditionally, the 'critical period' for sexual differentiation of the brain has been described to extend from E18 (and possibly as early as E16) to approximately day 10 post partum (MacLusky \& Naftolin 1981, Arnold \& Gorski 1984). However, application of testosterone as late as days 15-30 post partum and removal of the testis up to day 29 post partum can influence aspects of sexual behaviour and the size of the SDN-POA (Bloch \& Mills 1995, Bloch et al. 1995, Davis et al. 1995) and so for certain features the critical period may be more extensive. For others, e.g. the dark granule cell population of the accessory olfactory bulb, it may start as late as 1 or 2 weeks post partum, because administration of testosterone on day 14 post partum but not day 1 post partum can masculinize the number of these neurones (Segovia et al. 1999). 
More recently, evidence has accumulated to suggest that there are two critical periods for masculinization of the brain in the rat, one over the neonatal period (possibly extending into the prepubertal period) and a second over puberty, coincident with the increase in circulating gonadal steroids. During the second period, sexually differentiated organization of the brain is completed and the behavioural potential of the adult is fully achieved. At puberty, both steroid-dependent and steroid-independent changes occur in the brain, mainly concerned with pruning synaptic connections to refine neuronal circuitry and alter neuronal responses to external stimuli. Examples include a reduction in the dendritic length of neurones in the spinal nucleus of the bulbocavernosus (which is testosterone dependent), a reduction in the size of the medial nucleus of the amygdala (which is independent of testosterone) and development of responses to female pheromones with increased dopaminergic activity in the medial POA and enhanced $\mathrm{LH}$ and testosterone secretion. Without these and other changes, behaviour remains in a pre-pubertal state, with low levels of male sexual behaviour, extended stress responses and unchanged levels of aggression. It has been suggested that it is important for the steroiddependent and independent changes to occur concomitantly for full brain differentiation and that miss-timing will lead to atypical sexually differentiated behaviours and functions (Romeo 2003).

The critical period for sexual differentiation of the brain has not been defined in humans, but gender identity is thought to be established by the first year of life and structural differentiation principally occurs around 4 years of age (e.g. the size of the SDN-POA), but full sexual differentiation of the central nucleus of the bed nucleus of the stria terminalis is not manifest until adulthood (Swaab et al. 2003).

v) The relative effects of oestradiol and testosterone on sexual differentiation

In most mammals, the principal hormone masculinizing the brain is not testosterone itself, but its metabolite, oestradiol, acting on oestrogen receptors $\alpha$ and $\beta$ (ER $\alpha$ and $\beta$ ), which control separate aspects of differentiation. $E R \alpha$ is primarily involved in masculinization, while $E R \beta$ mediates defeminization of sexual behaviours, but not masculinization (Baum 2003, Patchev et al. 2004, Kudwa et al. 2006). The oestradiol synthesized locally in the brain is derived from testosterone after aromatization by the cytochrome $\mathrm{p} 450$ enzyme aromatase that is present in specific brain areas and whose expression is stimulated by testosterone acting on AR (Hutchinson 1997). Some sexually differentiated behaviour in rats require testosterone as well as oestradiol for their full expression e.g. male sexual behaviour, social play, aggression and open-field behaviour (Meaney 1989, Breedlove 1997, Sato et al. 2004). While the dimorphism in most sexually differentiated brain areas is dependent entirely on oestradiol, there are a number of regions that are masculinised by testosterone or DHT acting via AR. For example, the number of neurones in the spinal nucleus of the bulbocavernosus and the connectivity between GABA nerve terminals and hypothalamic $\mathrm{GnRH}$ neurones are greater in males than in females (Breedlove 1997, Sullivan \& Moenter 2004). In contrast, prenatal DHT treatment reduces the number of neurones in the locus coeruleus in males compared with females (GarciaFalgueras et al. 2005). The masculinization of the pattern of gonadotrophin release initially appears to be under the control of prenatally secreted testosterone, but postnatally both testosterone and oestradiol may be involved (Foecking et al. 2005). Progesterone derived from either the maternal system or produced locally in the brain is also involved in CNS sexual differentiation and may be part of a cascade originating with testosterone and progressing to oestradiol and then progesterone to induce full masculinization (Quadros et al. 2002a).

In species, in which oestradiol is the important masculinizing agent, it is vital to protect the female foetus from the high-circulating levels of maternal oestrogen and in the rat, this is achieved by the presence of $\alpha$-fetoprotein secreted by the liver and yolk sac. $\alpha$-Fetoprotein binds to oestradiol and prevents its passage into the brain. However, it does not bind to testosterone, which freely enters the brain where it is aromatized locally to oestradiol (Naftolin et al. 1991). In a few species, e.g. the guinea-pig and rhesus monkey, testosterone (and/or DHT) has been shown to be the main masculinizing hormone of the brain (Goy \& Resko 1972, Goldfoot \& Van Der Werff Ten Bosch 1975). Clinical evidence from individuals with genetic disorders suggests that testosterone is also the masculinizing agent in humans (Swaab 2004). Thus, males deficient in aromatase or expressing mutant ERs, exhibit male psychosexual behaviour and gender identity, in the face of lack of oestradiol synthesis or activity. Conversely, males deficient in ARs, but with functional ERs (androgen insensitivity syndrome), not only develop an external female phenotype and feminized sexually dimorphic behaviour, but also female gender identity (Grumbach \& Auchus 1999, Wilson 1999). Therefore, in humans, the absence of oestradiol activity does not prevent masculinization, but the absence of testosterone activity does. Moreover, in congenital adrenal hyperplasia, in which the foetus is exposed to high levels of adrenal testosterone due to a defective adrenal enzyme, female children display typical male activities and interests throughout life. However, in adulthood most women with congenital adrenal hyperplasia are heterosexual, although a greater percentage than in the population at large (30\% compared with $10 \%$ ) is homosexual, i.e. their sexual orientation is masculinized resulting in a preference for females (see Breedlove 1994, Cohen-Bendahan et al. 2005). 
vi) Indirect indicators of hormonal inducement of sexual differentiation

There is general agreement that the male brain exhibits greater asymmetry than the female brain (Wisniewski 1998, Gadea et al. 2003). It is also well established that the left cerebral hemisphere typically controls speech and language, while the right hemisphere controls non-verbal (e.g. spatial perception) and emotional processing. Males typically show superiority in spatial perception compared with females (Rilea et al. 2004), while females (especially in childhood) exhibit better speech and language skills (Smith \& Hines 2000, Kansaku \& Kitazawa 2001). These findings support the suggestion that in males, the right cerebral hemisphere is larger than the left. In view of the fact that the left side of the body is controlled by the right cerebral hemisphere and vice versa, a dominant right hemisphere would confer left-handedness and there is evidence to suggest that more males than females are lefthanded (Smith \& Hines 2000, Rilea et al. 2004). However, some authors of studies of handedness conclude the opposite, i.e. that the left hemisphere is dominant in males (Witelson \& Nowakowski 1991, Gadea et al. 2003, Cohen-Bendahan et al. 2004). The reason for this apparent conflict is not clear, but it is possible that handedness does not correlate with lateralization of either cortical size or function (Gadea et al. 2003).

Sexual differentiation of cerebral lateralization is thought to result from the prenatal secretion of testosterone in the male, based on clinical evidence from humans subjected to abnormal prenatal steroid exposure, i.e. congenital adrenal hyperplasia, prenatal exposure to diethylstilboestrol and females with opposite sex twins (Smith \& Hines 2000, Cohen-Bendahan et al. 2004). Animal studies have revealed that administration of testosterone or oestradiol to developing rats induces a male pattern of cerebral lateralization, such that males develop a thicker right cerebral cortex (Diamond 1991). Witelson \& Nowakowski (1991) have suggested that cerebral asymmetry is due to testosterone causing pruning of commissural fibres in the corpus callosum, leading to lateralization of cerebral functions in the male. On the other hand, the larger corpus callosum containing a greater number of axons interconnecting the cerebral hemispheres in human females potentially leads to a greater hemispheric exchange of information and therefore decreased functional asymmetry (Wisniewski 1998, Kansaku \& Kitazawa 2001). There are other potential indirect measures of hormonal inducement of sexual differentiation, such as otacoustic emissions and digit length ratios (see Cohen-Bendahan et al. 2005). However, reports about these parameters are conflicting and there is no direct evidence that pre and/or perinatal testosterone is involved in these sex differences (McFadden et al. 2005, Lippa 2006).

Feminization of the brain by steroids. Until the early 1980s, it was assumed that the brain became feminised by default in the absence of gonadal steroids. Döhler et al. (1984) questioned this assumption, when they found that administration of an anti-oestrogen compound to rats prevented normal female sexually differentiated cyclical release of LH and female sexual receptivity. They suggested that oestradiol is needed for a fully feminised brain, but in a much lower concentration than is required in the male and that there is a continuum of differentiation between the two sexes. Thus, the oestrogen requirement in male and female differentiation is quantitative rather than qualitative. A more recent finding goes further in identifying a proactive action of oestradiol on rat female brain structure. The corpus callosum (which is larger in the male rat) becomes enlarged in the female after ovariectomy in the second week of post partum and this enlargement can be prevented by the administration of oestradiol. This late effect of oestradiol contrasts with the earlier masculinizing effect on the corpus callosum observed in males before day 8 post partum (Bimonte et al. 2000).

\section{Steroid control of sexual differentiation of brain structure}

The steroid-induced structural changes in the brain are regionally specific and only occur in those brain regions expressing high densities of steroid receptors (Simerly 2002). Hormone-dependent brain sexual dimorphism was first reported as the larger size of neuronal nuclei and nucleoli in males compared with females and neonatally castrated males (Pfaff 1966). Subsequently, Raisman \& Field (1971) demonstrated a greater number of dendritic spines in the dorsal POA of the female compared with the male and Gorski et al. (1978) showed that the SDN-POA was four to six times larger in the male than female. Box 6 lists some of the many sexually differentiated nuclei in the brain.

It is now known that there is considerable variety in the nature of structural sexual dimorphisms in the brain and these include the size of specific brain regions, the extent of dendritic aborization, differences in the density and pattern of synaptic connections (e.g. spine and somatic synapses), size, number and phenotype of neurones in a particular region and astrocyte morphology (Matsumoto \& Arai 1997, McCarthy et al. 2002 a, Simerly 2002). In rodents, all of these differences are due to the effect of neonatal testosterone/oestradiol on programmed cell death, neurite growth, axon guidance and synaptogenesis (Fernandez-Galaz et al. 1997, Simerly 2002, see Boxes 6 and 7). Functionally, the structural sexual dimorphisms in individual brain regions give rise to sex differences in neuronal circuitry and thus differentiation of the responses to outside influences. For example, in the circuit underlying the regulation of $\mathrm{LH}$ and prolactin release, there are more projections from the AVPV to GnRH neurones in the POA and also to the tubero-infundibular dopaminergic system in the ARC nucleus in the female. Sensory information from the cortex can be transmitted to the hypothalamus by sexually differentiated pathways originating from vasopressin neurones in the bed nucleus 
Box 6 Sexually differentiated brain regions

\begin{tabular}{llll}
\hline Region & Volume larger in: & Notes & References \\
\hline VNO & Male & & $\begin{array}{l}\text { Segovia et al. (1999) } \\
\text { and Simerly (2002) }\end{array}$ \\
AOB & Male & & Ditto \\
meAmg & Male & & Ditto \\
PMv & Male & & Ditto \\
BNST: & Male & & Ditto \\
Posterior medial & Female & & \\
Anterior medial & Female & Seen only in adulthood in humans & \\
Anterior lateral & Male & & Swaab et al. (2003) \\
Central nucleus & Male & & Gorski et al. (1978) \\
SDN-POA & Female & & Nishizuka et al. (1993) \\
AVPV & Male & & Segovia et al. (1999) \\
SON & Male & Gorski et al. (1978) \\
SCN & Male & Swaab et al. (2003) \\
VMN & No sex diff. & Abizaid et al. (2004) \\
ARC & & More calbindin, vasopressin and VIP cells in females & Madeira et al. (2001) \\
& Female & More axodendritic spine and shaft synapses in male vlVMN & Matsumoto \& Arai (1980) \\
LC & Male & somatic synapses in males; no difference in spine synapses & Segovia et al. (1999) \\
SNB & Male (rat) & & Breedlove (1994, 1997) \\
AC & Female(human) & Noonan et al. (1998) \\
& No sex diff. & & Allen \& Gorski (1992) \\
& & & Lasco et al. (2002) \\
& & & Davies et al. (2004)
\end{tabular}

Abbreviations: VNO, vomeronasal organ; $\mathrm{AOB}$, accessary olfactory bulb; mAmg, medial amygdaloid nucleus; PMv, ventral premamillary nucleus; BNST, bed nucleus of the stria terminalis; SDN-POA, sexually dimorphic nucleus of the POA; AVPV, anteroventral periventricular nucleus; SON, supra-optic nucleus; SCN suprachiasmatic nucleus; VMN, ventromedial nucleus; ARC, arcuate nucleus; LC, locus coeruelus; SNB, spinal nucleus of the bulbocavernosus; AC, anterior commissure; vl, ventrolateral.

of the stria terminalis and the medial nucleus of the amygdala that project to the AVPV-ARC complex controlling neuroendocrine functions and to the SDNPOA-VMN complex, concerned with reproductive behaviour (Segovia et al. 1999, Simerly 2002, De Vries \& Panzica 2006, see Fig. 2).

Sexual dimorphism of the brain appears to influence reproductive function. For example, the cyclical pattern of gonadotrophin release in the female (as opposed to tonic release in the male) is associated with a larger AVPV in the female, containing more DA neurones and fewer enkephalin neurones than in the male. Moreover, the cyclical release of gonadotrophins is associated with a greater degree of dopaminergic dendritic aborization and synaptic density in the ARC of the female compared with the male (Matsumoto \& Arai 1997, McCarthy et al. 2002a, Simerly 2002). Similarly, the size of the mPOA and dendritic spine density within it have been positively correlated with the expression of male sexual behaviour (Rhees et al. 1999, Amateau \& McCarthy 2004).

\section{Mediators of steroid action}

Steroids exert their effects via specific receptors, oestrogen on $E R \alpha$ and $E R \beta$, testosterone and DHT on AR and progesterone on PRs. The numbers of these receptors in certain regions of the hypothalamus are sexually differentiated. The circulating level of oestradiol (derived from the perinatal surge of testosterone) starts to rise in the neonatal male rat after $4-5$ days post partum; ER $\alpha$ (in the POA, VMN and ARC) and ER $\beta$ (in the VMN) mRNA and protein are suppressed so that their receptor density is lower in the male than in the female (DonCarlos et al. 1995, Kuhnemann etal. 1995, Ikeda etal. 2003). These sex differences in ER $\alpha$ expression are maintained to at least day 28 post partum (Kuhnemann et al. 1995), whereas the sex difference in ER $\beta$ expression in the VMN has disappeared by day 21 post partum (Ikeda et al. 2003). In contrast, to the $V M N, E R \beta$ immunoreactivity in the SDN-POA is significantly higher in males than females on day 18 post partum (Dakin et al. 2007). There is also a sex difference in the distribution of $E R \beta m R N A$ and immunoreactivity in the AVPV, from the first week post partum, such that there are more ER $\beta$-positive cells in the medial-most portion in the female than in the male (Orikasa et al. 2002). In contrast to the suppression of $E R \alpha$, the rise in neonatal oestradiol increases AR mRNA and PR immunoreactivity in neonatal males compared with females. (McAbee \& DonCarlos 1999, Quadros etal. 2002b). It is interesting to note that the increase in $A R$ ir in the foetal reproductive system is regulated by $\mathrm{DHT}$, whilst non-aromatizable androgens do not affect AR mRNA in the neonatal brain (Bentvelsen etal. 1995, McAbee \& DonCarlos 1999). 
Box 7 Actions of oestrogens on neuronal development, growth and survival

1. Induces or prevents programmed cell death/apoptosis

(a) Oestradiol can act via caspase-dependent or independent pathways (caspase is a cysteine protease, which cleaves intracellular proteins resulting in cell death).

(b) Oestradiol can regulate pro-apoptotic (e.g. BAX) or anti-apoptotic(e.g. Bcl-1) proteins in a brain region specific manner.

\section{References}

Simerly (2002), Zup et al. (2003), Forger et al. (2004), Forger (2006)

2. Stimulates neurite growth

(a) Neonatal oestrogen alters the morphology of astrocytes and in adulthood these astrocytes do not have the plasticity to alter in response to the endocrine milieu. Astrocytes are the source of neurotrophs, which can alter dendritic growth. They also provide 'scaffolding' for migrating neurones.

(b) Oestradiol can regulate the production of neurotrophs and their activity by altering their receptor levels e.g. nerve growth factor (NGF) and its receptors p75 and trKA, brain-derived neurotrophic factor (BDNF) and its receptor trkB, insulin-like growth factor (IGF-I), its binding proteins and its receptors. Neurotrophs (particularly IGF-I) and oestradiol can synergise as cross-talk can occur between neurotrophins and oestrogen receptors. Growth promoting co-factors such as Growth Associated Protein 43 (GAP 43) are stimulated by oestradiol.

\section{References}

Fernandez-Galaz et al. (1997), Segovia et al. (1999), Simerly (2002), McCarthy et al. (2002a)

3. Induces neuronal cell migration

Oestradiol induces site specific cell migration. This may be due to oestrogen-induced alteration in astrocyte morphology.

References

Henderson et al. (1999), Tobet (2002), McCarthy et al. (2002a)

4. Induces synaptogenesis

Oestradiol induces phosphorylation of CREB forming $\mathrm{pCREB}$, which promotes synaptogenesis.

References

Simerly (2002), Auger (2004)

Steroid receptors are all intracellular proteins and on binding with their ligand become transcription factors that activate gene expression. They usually dimerize once bound to their steroid ligand and if two receptor types e.g. ER $\alpha$ and $E R \beta$ are co-localised, this can lead to heterodimerization and hence a different transcriptional action (Ikeda et al. 2003). Steroids can also act nongenomically, coupling to and phosphorylating such intracellular messengers as MAP kinase, DAG/IP ${ }_{3}$, AkT and CAMP response element binding protein (CREB), each being involved in aspects of cell survival, synaptogenesis or induction of neurotrophin genes (Falkenstein et al. 2000, Simerly 2002, Mhyre \& Dorsa 2006). Sex differences in steroid activation of these intracellular systems may be due to differences in receptor density or dimerization. In addition, sexual differentiation can exist downstream of the steroid receptor, in the response of intracellular systems. For example, ER $\alpha$-induced phosphorylation of CREB is greater in the female than in the male ventrolateral $\mathrm{VMN}$, despite the fact that $\mathrm{ER} \alpha$ density is similar in the two sexes (Ábrahám \& Herbison 2005).

The potential diversity of steroid actions is also increased by:

(a) The existence of multiple co-activators e.g. steroid receptor co-activator- 1 and CREB-binding protein (CBP) or co-repressors. These are agents that increase or decrease the accessibility of DNA binding sites, so that transcription factors (such as 


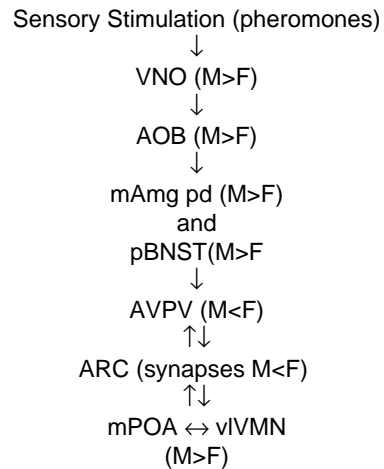

Abbreviations: AOB, accessory olfactory bulb; ARC, arcuate nucleus; AVPV, anteroventra periventriclar nucleus of the hypothalamus; $\mathrm{mAmg} \mathrm{pd,} \mathrm{postero-dorsal} \mathrm{region} \mathrm{of} \mathrm{the} \mathrm{medial}$ nucleus of the amygdala; mPOA, medial preoptic area; pBNST, principal nucleus of the stria terminalis; SDN-POA, sexually dimorphic nucleus of the POA; vIVMN, ventro-lateral region of the ventromedial nucleus of the hypothalamus; $\mathrm{VNO}$, vomerosnasal organ. $\mathrm{M}$, male; $\mathrm{F}$, female; >, greater than; $<$, less than.

Modified from Simerly, 2002

Figure 2 Sexually dimorphic pathways in rat forebrain.

the ligand-bound steroid receptors) can bind differentially depending on their co-localization with specific co-activators or co-repressors. Ligand-bound steroids can alter their own efficacy by stimulating the expression of these co-activators or co-repressors (Auger 2004).

(b) Steroids can exert effects on cell membranes including depolarization via cAMP or cGMP pathways, which can act synergistically with the classic genomic actions of oestrogen (Segovia et al. 1999). For example, depolarization induces release of neurotrophins e.g. insulin-like growth factor (IGF-I) and tyrosine kinase type B from glial cells (themselves differentiated by neonatal oestrogen; see Box 7), which act synergistically with oestradiol to enhance the whole gamut of neuronal regulation i.e. programmed cell death, axon growth and synaptogenesis (Fernandez-Galaz et al. 1997, Carrer \& Cambiasso 2002, McCarthy et al. 2002a).

(c) Interaction between intracellular peptidergic factors and steroids. Oestradiol can upregulate expression of a variety of neurotophins and their receptors and in turn, this may lead to synergistic actions between the neurotrophins and the ligand-bound steroid receptors. Some neurotrophins (e.g. IGF-I) can also activate ERs independently of steroid ligand binding and some can act directly on intracellular pathways that are affected by oestradiol. Thus, neurotrophins enhance neuronal growth either because they interact with oestrogen and/or its receptors or because they act on similar pathways to oestrogen after being upregulated by it (Fernandez-Galaz et al. 1997, Segovia et al. 1999, Simerly 2002). Box 7 lists some of the actions of oestradiol on neuronal development, growth and survival.
From the summary given above, it is possible to envisage how a single endocrine environment can have different effects on individual regions of the nervous system. For example, inducing programmed cell death in the male AVPV, perhaps by increasing the activity of the pro-apoptotic protein, Bax (Forger et al. 2004) and inhibiting programmed cell death in the SDN-POA and the spinal nucleus of the bulbocavernosus, by increasing expression of the anti-apoptotic protein Bcl-2 (Zup et al. 2003). Similarly, regional differences in steroid-induced neurite growth and synapse formation could be due to region-specific regulatory pathways. The enhanced dendritic-spine growth in the male compared with the female POA results from oestrogen upregulation of prostaglandin $\mathrm{E}_{2}\left(\mathrm{PGE}_{2}\right)$, which then activates glutamate systems specifically in the POA. This pathway appears to be physiologically important because inhibition of $\mathrm{PGE}_{2}$ synthesis with indomethacin in neonatal male rats reduces dendritic spine density and also male sexual behaviour in adulthood. Conversely, neonatal administration of $\mathrm{PGE}_{2}$ to females increases both neuronal dendritic spine growth in the POA and male sexual behaviour in adulthood to levels normally present in adult males (Amateau \& McCarthy 2004).

\section{The effect of environmental endocrine agents on sexual differentiation of the central nervous system}

In multiparous species, the steroid environment of the foetus in utero can differ significantly according to the sex of adjacent foetuses. A foetus adjacent to male foetuses will be exposed to the testosterone emanating from them, which can influence aspects of sexually differentiated morphology, physiology and behaviour. Thus, female foetuses adjacent to males can exhibit some masculinization, such as a longer ano-genital distance, a larger SDN-POA, masculinization/defeminization of sexual behaviour and increased aggressive behaviour, compared with female foetuses situated next to other females (Ryan \& Vandenbergh 2002, Pei et al. 2006).

Studies of the effects of EDs and diethylstilboestrol on sexual differentiation of the rodent brain indicate that exposure to oestrogenic compounds masculinizes female brain morphology and the regulation of gonadotrophin release and behaviour. Conversely, the same oestrogenic agents feminize the male brain, as indicated by the expression of a variety of sexually differentiated socio-sexual and non-social behaviours (see Box 4). A smaller number of reports support a similar masculinization of the female brain and feminization of the male brain in response to anti-androgenic EDs (see Box 4). Female rodents, in which the masculinizing effects of pre and perinatal oestradiol exposure on the CNS are clearly established, would be expected to respond to the masculinizing effects of oestrogenic EDs. Furthermore, since the balance of oestrogen:androgen activity appears 
to be important for sexual differentiation (Vidaeff \& Sever 2005), anti-androgenic EDs may disrupt the balance in favour of oestrogenic activity. In male rodents, extra oestrogenic activity may not necessarily be expected to induce further masculinization, but the finding that oestrogenic EDs induce feminization is surprising. The disruption of the normal oestrogen:androgen balance may be the cause of this feminization, because both oestrogens and androgens are required for full masculinization of the male brain (see section Steroid control of brain-regulated functions and behaviour). Another possibility relies on the variety of potential actions of certain EDs, which give rise to agonistic or antagonistic oestrogenic and androgenic effects, depending on the background endocrine milieu.

In humans, where the role of oestrogen in sexual differentiation of the brain is debateable (see section: Steroid action on behaviour), reports of the effects of prenatal exposure to diethystilboestrol are conflicting. Some authors report no effects on gender-related behaviours (Lish et al. 1991, Newbold 1993, Titus-Ernstoff et al. 2003), while others report that diethystilboestrol masculinizes aspects of sexual (Ehrhardt et al. 1985, Reinisch et al. 1991) and non-sexual behaviours in a small proportion of women depending on the time of exposure; early prenatal exposure appears to masculinize hand preference (increases left-handedness), while late prenatal exposure masculinizes (improves) visuospatial abilities (Hines \& Sandberg 1996, Smith \& Hines 2000). These findings appear to support the suggestion that there are sensitive periods when different brain regions and thus behaviours, are susceptible to steroid hormones (Cohen- Bendahan et al. 2005). Prenatal exposure to the anti-androgenic EDs (e.g. polychlorinated biphenols) masculinize prepubertal play in girls and feminize prepubertal play in boys, although another group of polychlorinated anti-androgen compounds (dioxins) feminizes play behaviour in both boys and girls (Vreugdenhil et al. 2002). By and large, the few reports of the effects of oestrogenic and anti-androgenic EDs in human males, suggest feminization of prepubertal play, visuospatial ability, gender identity and lateralization of cerebral hemisphere function (Reinisch \& Sanders 1992, Vreugdenhil et al. 2002, Beyer et al. unpublished). Therefore, the evidence suggests that EDs act similarly on rodent and human brains to masculinize females and feminize males, although only a minority of humans are affected and the responses to individual EDs are variable.

\section{The role of neurotransmitters in sexual differentiation of the brain}

If neonatal steroids alter neuronal survival, growth and connections, thus inducing neuronal sexual dimorphism, it would reasonable to assume that neurotransmitter activity could also be sexually differentiated. Indeed, an example has already been given above (see section:
Steroid control of sexual differentiation of brain structure) in that the neonatal steroid surge has been demonstrated to reduce the number of DA neurones in the AVPV, and dendritic arborization and synapses of DA neurones in the ARC (Matsumoto \& Arai 1997, Simerly 2002). Other neurotransmitter systems that show sexual differentiation are GABA, 5-hydroxytryptamine (5-HT), noradrenaline (NA) and endogenous opiates (see Box 8 for further examples of neurotransmitters and neuromodulators). Neonatal steroids affect the concentrations, distribution and activity of sexually differentiated these neurotransmitters, which in turn appear to mediate the effect of the steroids. Furthermore, some neurotransmitters can feedback to influence the prenatal/neonatal action of the steroids and thence physiological and behavioural functions in adulthood. A summary of the role of individual neurotransmitters in sexual differentiation is given below.

\section{$\gamma$-Aminobutyric acid}

In certain nuclei of the hypothalamus and limbic system (VMN, ARC, dorsomedial nucleus, hippocampus and cortical amygdala), GABA and its rate limiting synthetic enzyme, glutamic acid decarboxylase mRNA, together with GABA A receptors, are more prevalent in male than in female rats during the early postnatal period (days 1-4 post partum), but by day 15 post partum the sex differences have disappeared (Davis et al. 1996, 1999). These sex differences are oestrogen-dependent and as GABA has a similar trophic action to oestradiol in the CNS, i.e. influencing neuronal survival, astrocyte morphology and thence cell migration, neurite extension and synaptogenesis, GABA may mediate the steroid's action (Davis et al. 1999, McCarthy et al. 2002a, Mong \& Blutstein 2006, see Box 7). The trophic effect of GABA is only manifest over a short neonatal period when, in contrast to its hyperpolarizing effect in the adult, GABA induces depolarization (see Box 9). This depolarization increases calcium ion $\left(\mathrm{Ca}^{++}\right)$influx into neurones, which in turn increases phosphorylation of CREB, promoting neuronal survival, neurite growth and synapse formation (Segovia et al. 1999, McCarthy et al. $2002 b$ ). This excitatory phase of GABA activity peaks on day 1 post partum and is fully reversed to a hyperpolarizing activity by day 6 in the hypothalamus and day 13 in the hippocampus (McCarthy et al. 2002b). The mechanism causing GABA's change from depolarizing to hyperpolarizing activity is explained in Box 9. In vitro studies on foetal hypothalamic neurones have revealed that oestradiol enhances the rise in intracellular $\mathrm{Ca}^{++}$ induced by GABA A receptor stimulation (Perrot-Sinal et al. 2001) and therefore, the rise in neonatal oestrogen in males in vivo may act to delay the switchover from depolarizing to hyperpolarising activity and so allow GABA to exert its trophic effect for a longer period. This view is supported by the fact that neonatal administration of the GABA A agonist muscimol, inhibits 
Box 8 Sexually differentiated hypothalamic neurotransmitters/neuromodulators Details of $5 \mathrm{HT}, \mathrm{GABA}$, dopamine, noradrenaline and opiates are presented in the text

\begin{tabular}{llll}
\hline Neurotransmitter & Hypothalamic region & Predominant & References \\
\hline Vasopressin & SCN & Male & De Vries et al. (1981) \\
Cholecystokinin & periVN \& DMN & Female & Micevych et al. (1987) \\
& HPOA & Male & Diez-Guer (1992) \\
Neuropeptide Y & POA (1987) \\
& ARC & Andr. Female & Urban et al. (1993) \\
Neurotensin & MBH & Andr. Female & Diez-Guerra et al. (1987) \\
& AVPV & Female & Alexander et al. (1991) \\
Calcitonin gene- & AVPV \& mPOA & Female & Herbison (1998) \\
Related peptide & ARC \& DMN & Male & Leclercq \& Herbison (1996) \\
Kisspeptin V & AVPV \& periVN & Female & Clarkson \& Herbison (2006) \\
\hline
\end{tabular}

Abbreviations: SCN, suprachiasmatic nucleus; periVN, periventricular nucleus; DMN, dorsomedial nucleus of the hypothalamus; mPOA, medial preoptic nucleus; POA, preoptic area; ARC, arcute nucleus; $\mathrm{MBH}$, mediobasal hypothalamus; AVPV, anteroventral periventricular nucleus.

phosphorylation of CREB in the female mPOA and VMN, but stimulates it in males. This sex difference could be due to the prolonged period of GABA A-induced depolarizing activity in males (Auger et al. 2001).

Neonatal oestradiol regulates the transient sex differences in neonatal GABA activity. In contrast, prenatal androgens may induce changes in the hypothalamic GABA system that is maintained in adulthood. When pregnant mice are treated on E16-18 with DHT, the female offspring exhibit a greater connectivity between GABA nerve terminals and $\mathrm{GnRH}$ neurones in adulthood (indicated by an increased frequency and size of postsynaptic currents that are independent of action potentials), compared with untreated females. This change in connectivity may be due to an increase in number of dendrites and synapses and/or an increase in efficacy of the GABA A receptors on the $\mathrm{GnRH}$ neurones (Sullivan \& Moenter 2004). The enhanced inhibitory effect of GABA in females may be the cause of the 4-6 day delay in the rise of gonadotrophin release that occurs after gonadectomy; in males this rise in gonadotrophin release occurs within a few hours of gonadectomy (Hood \& Schwartz 2000). In adults, oestradiol exerts a sex-specific effect on the daily release of GABA in the $\mathrm{mPOA}$, inducing an early morning rise in females. Increases in GABA release also occur in males, but they occur sporadically and are not confined to the morning. It has been suggested that this part of the sexually differentiated mechanisms controlling induction of the LH surge is induced by oestradiol (Mitsushima et al. 2003, Tin-Tin-Win-Shwe et al. 2004).

\section{5-Hydroxytryptamine}

In adults, the cerebral 5-HT system is sexually differentiated with higher activity in certain regions of the female compared with the male brain and this difference is dependent upon neonatal steroids (Simerly et al.

Box 9 The switch of GABA-induced depolarisation to hyperpolarization

The GABA A receptor is a chloride ionophore selectively permeable to chloride ions $\left(\mathrm{Cl}^{-}\right)$and bicarbonate ions. Chloride ions can flow in either direction depending on the concentration gradient. In the adult, GABA is an inhibitory transmitter inducing hyperpolarization because it opens up the chloride ionophore and as intracellular $\mathrm{Cl}^{-}$concentrations are low in the adult, the anionic gradient favours influx into the cell at the resting membrane potential, resulting in negative intracellular charge i.e. hyperpolarization and synaptic inhibition. The low intracellular concentration of $\mathrm{Cl}^{-}$is due to the action of a $\mathrm{KCl}$ co-transporter $\left(\mathrm{KCC}_{2}\right)$. In the neonate, $\mathrm{KCC}_{2}$ expression is low and intracellular $\mathrm{Cl}^{-}$concentration is allowed to rise. This accumulation is further increased by another co-transporter for $\mathrm{Na}^{+}-\mathrm{K}^{+}-2 \mathrm{Cl}\left(\mathrm{BSC}_{2}\right.$ also called NKCC1), which occurs at higher levels in the neonate than the adult and enhances passage of $\mathrm{Cl}^{-}$into cells. On opening the chloride ionophore (by GABA) in the neonate, there is a flow of $\mathrm{Cl}^{-}$out of the cell and thence depolarization. The depolarization causing the L-type voltage-gated $\mathrm{Ca}^{++}$channel to open and allow an influx of $\mathrm{Ca}^{++}$into the cell. GABA controls its own switchover as increased intracellular $\mathrm{Ca}^{++}$induces an increase in $\mathrm{KCC}_{2}$ expression and so lowers intracellular $\mathrm{Cl}^{-}$, eventually leading to the hyperpolarizing action of GABA.

Summarised from Davis et al. (1996) and McCarthy et al. (2002a). 
1985a, Borisova et al. 1996). In the neonatal period, sex differences are variable and transient. On day 1 post partum, 5-HT activity is greater in males than females in the whole hypothalamus, but this difference disappears by day 10 post partum. However, greater 5-HT activity can still be detected in the male POA on day 10 post partum (Wilson et al. 1986, Lesage et al. 1996, Reznikov \& Nosenko 1996). On day 12 (Ladosky \& Gaziri 1970) or 14 (Wilson et al. 1986) post partum, there is a transient decrease in hypothalamic 5-HT and 5-hydroxyindole acetic acid (the chief metabolite of 5-HT) in males. This decrease is also steroid dependent even though it occurs approximately 12 days after the neonatal testosterone surge (Giulian et al. 1973). The fall in 5-HT activity appears to be essential for complete masculization of the brain, because administration of a 5-HT precursor, 5-hydroxytryptophan or the 5- $\mathrm{HT}_{2}$ receptor agonist, (-)[2,5dimethoxy-4-iodophenyl]-2-amino propane; $(-)$ DOI, to males or androgenised females over a period that covers the transient fall in endogenous 5-HT (days 8-16 post partum) feminizes several sexually differentiated functions and behaviours i.e. LH release in response to steroids, sexual orientation, male and female sexual behaviour and aggression (Wilson et al. 1998, Murray et al. 2004). Such treatment also feminizes the size of two sexually dimorphic hypothalamic nuclei, the SDN-POA and the AVPV (Murray et al. 2004). Conversely, treatment with a 5-HT synthesis inhibitor, parachlorophenylalanine, enhances masculinization and defeminization (Wilson et al. 1998). Manipulation of 5-HT activity over the first week post partum in males has no effect on subsequent adult reproductive function or behaviour, nor does 5-HT treatment over either the first or second week post partum affect normal females that have not had prior exposure to testosterone (Jarzab \& Döhler 1984, Wilson et al. 1986, 1998). These findings indicate that the feminizing effect of agents that raise $5-\mathrm{HT}$ activity is due to the fact that they counteract the fall in endogenous 5-HT occurring on day $12 / 14$ and that 5-HT antagonises the neonatal effects of testosterone/oestradiol. 5-HT has been demonstrated to antagonise the anti-apoptotic effect of testosterone on the spinal nucleus of the bulbocavernosus (Cowburn \& Payne 1994). Recent studies into the effect of the $5-\mathrm{HT}_{2}$ agonist (-) DOI given over days 8-16 post partum show that, while the numbers of $E R \alpha, E R \beta$ and PR ir cells are not affected by this treatment, AR numbers are significantly reduced in the male and androgenised female SDN-POA and AVPV (Dakin et al. 2007). Therefore, (-)DOI treatment appears to inhibit the increase in $A R$ expression normally induced in male rat pups by the rise in oestradiol derived from the neonatal testosterone surge (McAbee \& DonCarlos 1999). The (-)DOIinduced reduction in ARs in the male and androgenised female hypothalamus correlates with its feminizing effects on pattern of $\mathrm{LH}$ release and male sexual and agonistic behaviour, emphasizing the fact that a critical
AR number is required to allow neonatal testosterone to induce complete masculinization. It is possible that the reduction in ARs reduces the testosterone-induced activation of aromatase necessary to produce oestradiol and thence masculinization (Hutchison 1997) or the 5-HTinduced reduction in ARs artificially advances the pubertal reduction in $A R$, so that it does not occur at the critical period during puberty for normal and final development and differentiation of the brain (see section Steroid control of brain-regulated functions and behaviour, Romeo 2003). It is also possible that (-)DOI and ARs interact at intracellular sites, because activation of both $5 \mathrm{HT}_{2}$ receptors and ER/AR can stimulate $\mathrm{Ca}^{+}{ }^{+}$release and activate AC/CAMP, DAG/IP3 and MAP kinase pathways, all of which are involved in neonatal brain development (Mattson 1988, Falkenstein et al. 2000).

\section{Dopamine}

Earlier in this article (see section: Genetic control of sexual differentiation in the brain; Chromosomal sex), sex differences in the mesencephalic DA system were described. In this section the focus is on the hypothalamic DA system, which is sexually differentiated in utero with greater activity (higher concentrations of DA and a greater DA turnover rate) in females compared with males, despite the fact that $\mathrm{TH}$-ir cell numbers are similar in the two sexes. This sexual differentiation is independent of steroids, because it is present in foetal diencephalic cell cultures taken on E14, before steroid secretion commences. Moreover, the application of steroids to such cultures has no effect on the sexual differentiation of the DA system (Reisert \& Pilgrim 1991). After birth, sex differences in hypothalamic DA are still present, but they are steroid dependent and their pattern of expression is regionally specific and the sex differences are reversed in the mediobasal hypothalamus compared with the prenatal period, with a greater activity in the male. In vitro studies of the whole or mediobasal hypothalamus have revealed that tissue exposed to testosterone (or oestradiol), either by administration of exogenous steroid or because the tissue originated from males, exhibits higher rates of DA synthesis and release compared with tissue not exposed to steroids (Kawashima \& Takagi 1994, Melnikova et al. 1999). Similar findings have been obtained in vivo, when exposure to neonatal steroids induced greater concentrations and turnover of hypothalamic DA (Vathy et al. 1995, Lesage et al. 1996, Reznikov \& Nosenko 1996). The greater activity of DA in the male mediobasal hypothalamus may mediate some of the masculinizing effects of oestradiol. However, DA may also exert a masculinizing effect that is independent of steroids. DA has been shown to exert a ligand-independent activation of PRs (Power et al. 1991) and more recently DA has been demonstrated to exert a similar effect on ERs (Olesen et al. 2005). Two of the masculinizing effects of 
neonatal oestradiol are an increase in PRs in the CNS and an increase in rough and tumble (social) play in male pups compared with females. Administration of the DA1 agonist (SKF 38393) on day 1 post partum has similar effects and these can be prevented by prior treatment with an ER antagonist (Olesen et al. 2005). The higher DA activity in the mediobasal hypothalamus of males in the neonatal period, whether mediating the action of oestradiol or acting directly on ERs, maybe important for masculinizing and defeminizing functions/behaviours in adulthood. This possibility is indicated by the facts that DA antagonists, given neonatally, reduce male sex behaviour in adulthood and prevent constant oestrus and anovulation in females normally induced by neonatally administered steroids (Kikuyama 1962, Hull et al. 1984, Gonzales et al. 2000).

In contrast to its effect on the mediobasal hypothalamus, neonatal testosterone has no effect on DA activity in cell cultures taken from the POA (Kawashima \& Takagi 1994) or in the POA in vivo and there are no dopaminergic sex differences in this region of the hypothalamus (Reznikov \& Nosenko 1996). In fact, there is a virtual absence of DA neurones in the medial POA (Simerly et al. 1986). However, histological studies of the AVPV show that the number of DA neurones is three to four fold greater and there are two to four times more DA fibres in females than in males (Simerly et al. 1985b). The results from experiments on ER $\alpha$ knockout mice indicate that this sexual differentiation is due to an inhibitory effect of the neonatal steroid surge in males, exerted via oestradiol acting on ER $\alpha$ (Simerly et al. 1997). There are more efferents from the female AVPV projecting to gonadotrophin releasing hormone neurones and to the ARC than in males and the rate of DA turnover in both the ARC and median eminence is higher in females than males (Demarest et al. 1981, Gu \& Simerly 1997). It is likely that this enhanced DA activity in the AVPV and ARC/median eminence complex is important for the regulation of the cyclical release of gonadotrophins in females (Simerly 2002).

\section{Noradrenaline}

On day 10 post partum, NA turnover rate in the POA is higher in males than in females, (as assessed by inhibition of synthesis with $\alpha$-methyl tyrosine), while the content of NA in the male POA on day 10 and 33 post partum is lower than in the female (Vathy et al. 1995, Reznikov \& Nosenko 1996), indicating a greater turnover of NA in this region in the male during the neonatal period. It is possible that the greater release of NA in the male is due to oestradiol derived from the perinatal testosterone surge (Reznikov \& Nosenko 1987). Recent assessments of NA content and turnover rate in the mediobasal hypothalamus do not indicate any sexual differentiation (Reznikov et al. 2004). The data from the POA suggest that NA mediates the masculinising effect of oestradiol. There is some pharmacological evidence to suggest that NA acting on $\alpha$-adrenergic receptors induces defeminization (Jarzab et al. 1987) and acting on $\beta_{2}$-adrenergic receptors stimulates masculinization, in particular increasing the size of the SDN-POA not only in females but also in males, in which the SDN-POA is already larger than in females (Jarzab et al. 1990). However, NA acting on $\beta_{1}$-adrenergic receptors appears to have a feminizing effect. In females it prevents the induction of constant oestrus normally produced by neonatal testosterone (Raum \& Swerdloff 1981) and in males it increases female and decreases male sexual behaviours (Döhler 1991). This $\beta_{1}$-adrenergic effect may result from inhibition of the aromatization of testosterone to oestradiol (Raum et al. 1984, Canick et al. 1987) or preventing nuclear uptake of oestradiol (Raum et al. 1984). See Box 10 for a summary of the actions of DA and NA on sexually differentiated functions.

\section{Opiates}

There are four endogenous opiates in the hypothalamus; met-and leu-enkephalin, dynorphin- $A$ and $\beta$-endorphin. Only enkephalin neurones and fibres are sexually differentiated, with more enkephalin neurones in the AVPV (Simerly et al. 1988) and medial POA (Segarra et al. 1998) of the male than the female and a denser plexus of encephalin-containing fibres projecting to the medial POA in males (Ge et al. 1993). Conversely, projections from the VMN to the AVPV are denser in females than in males (Hoffman et al. 1996). Administration of oestradiol during the pre-pubertal period induces an increase in the size of the enkephalin neurones in the female but not male POA and it increases proenkephalin expression in the POA of both sexes, with the response being greater in females. Therefore, it appears that sexual differentiation of the enkephalin system (which is normally larger in males) is established during the usual neonatal period, but nearer to the time of puberty, there is a sexually differentiated response of the enkephalin system to oestradiol that is greater in the female than in the male (Segarra et al. 1998). It has been suggested that the higher levels of proenkephalin in the male POA are necessary for suppressing reproductive behaviour and function pre-pubertally (Segarra et al. 1998), while in the female nearing puberty and in adulthood, the enkephalin system is involved in the regulation of the cyclical pattern of $\mathrm{LH}$ release and sexual behaviour (Romano et al. 1990, Simerly 2002).

While enkephalins are the main sexually differentiated endogenous opiates, most of the experiments assessing the effects of exogenous opiates employ morphine, $\beta$-endorphin or the $\mu$-antagonist naloxone. Morphine is a $\mu$-agonist and $\beta$-endorphin and the enkephalins act predominantly on $\mu$ and $\delta$ receptors (Alexander \& Peters 1998). The results of most experiments indicate that opioid activity is required for feminization in females (for cyclical release of LH and female sexual behaviour; 


\begin{tabular}{|c|c|c|c|}
\hline Catecholamines & AVPV & $\begin{array}{l}\text { Hypothalamic areas } \\
\text { POA }\end{array}$ & $\mathrm{MBH}$ \\
\hline Dopamine concentration/activity & Higher in females Simerly et al. (1985b) & $\begin{array}{l}\text { No sex difference and } \\
\text { neurones sparse (Simerly } \\
\text { et al. 1986, Kawashima \& } \\
\text { Takagi 1994, Reznikov \& } \\
\text { Nosenko 1996) }\end{array}$ & $\begin{array}{l}\text { Higher in males (Kawashima } \\
\text { \& Takagi 1994, Reznikov \& } \\
\text { Nosenko 1996) }\end{array}$ \\
\hline Function & $\begin{array}{l}\text { Regulates cyclical release of LH } \\
\text { (feminization; Simerly 2002) }\end{array}$ & & $\begin{array}{l}\text { Induces masculinization of } \\
\text { behaviour (Hull et al. 1984, } \\
\text { Olesen et al. 2005) }\end{array}$ \\
\hline $\begin{array}{l}\text { Noradrenaline concentration/ } \\
\text { activity } \\
\text { Function on: }\end{array}$ & & $\begin{array}{l}\text { Higher in males (Reznikov \& } \\
\text { Nosenko 1996) }\end{array}$ & $\begin{array}{l}\text { No sex (Reznikov et al. 2004) } \\
\text { difference }\end{array}$ \\
\hline$\alpha$-receptors & & $\begin{array}{l}\text { Defeminization of behaviour } \\
\text { (Jarzab et al. 1987) }\end{array}$ & \\
\hline$\beta_{1}$-receptors & & $\begin{array}{l}\text { Feminization of behaviour } \\
\text { (Jarzab et al. 1990) }\end{array}$ & \\
\hline$\beta_{2}$-receptors & & $\begin{array}{l}\text { Masculinization of } \\
\text { behaviour } \\
\text { (Raum \& Swerdloff 1981, } \\
\text { Döhler 1991) }\end{array}$ & \\
\hline
\end{tabular}

Abbreviations: AVPV anteroventral periventricular nucleus; POA preoptic area; MBH mediobasal hypothalamus.

Lira et al. 1986, Romano et al. 1990) and induces feminization in males (Sandberg et al. 1990, Johnston et al. 1992). Reznikov et al. (2005) have also suggested that endogenous opiates are the mediators of the feminizing effect induced by stress. However, there are conflicting reports that suggest opioids given over late pregnancy or on day 1 post partum, can cause defeminization in females, reducing female sexual behaviour and can cause increased masculinization in males, enhancing sexual and aggressive behaviour. These latter results may reflect the importance of the larger enkephalin neuronal system in the medial POA and AVPV of neonatal males compared with females, while the later (around puberty) increased responsiveness of the female enkephalin system to oestradiol may underlie the feminizing effects of opiates (Segarra et al. 1998).

\section{Conclusion}

There have been substantial advances in the understanding of the genetic and the hormonal control of sexual differentiation of the reproductive system and brain over the last 60 years. Although many questions have been answered, as in all scientific endeavours, new questions have arisen and gaps in our understanding continue to appear. For example, TDF is now known to be the $S R Y$ gene, but whether it stimulates a cascade of masculinizing genes or acts as a repressor is still not clear and the exact roles of many of the masculinizing genes also remain unresolved. Moreover, little is known about the genetic regulation of the sexual differentiation of the female reproductive system and brain. These topics currently provide important fields of investigation.
Many aspects of the mechanisms of actions of the hormonal regulation of sexual differentiation of the reproductive system and the brain have been elucidated. In the brain, this has led to an understanding of the involvement of a huge variety of intracellular pathways that mediate steroid actions. The involvement of neurotransmitters in sexual differentiation of the brain and behaviour is also well established, although the precise roles of most of them remain to be elucidated, especially, since different neuronal systems with a common neurotransmitter can have opposing effects. In most cases investigated, the neurotransmitters act as mediators of steroid action, although some 'feed-back' and act as modulators of steroid activity. Further investigations of the fundamental controls of sexual differentiation in a variety of species will be necessary to fully illuminate the regulation of physiological, psychological and behavioural regulation of sex differences.

\section{Acknowledgements}

The authors declare that there is no conflict of interest that would prejudice the impartiality of this scientific work.

\section{References}

Abizaid A, Mezei G, Sotonyi P \& Horvath TL 2004 Sex differences in adult suprachiasmatic nucleus neurons emerging late prenatally in rats. European Journal of Neuroscience 19 2488-2496.

Ábrahám IM \& Herbison AE 2005 Major sex differences in nongenomic estrogen actions on intracellular signalling in mouse brain in vivo. Neuroscience 131 945-951. 
Aiyer MS \& Fink G 1974 The role of sex steroid hormones in modulating the responsiveness of the anterior pituitary gland to luteinizing hormone releasing factor in the female rat. Journal of Endocrinology 62 553-572.

Alexander SPH \& Peters JA 1998 Receptor and ion channel nomenclature. Trends in Pharmacological Sciences Supplement 9 58-59.

Alexander MJ, Kiraly ZJ \& Leeman SE 1991 Sexually dimorphic distribution of neurotensin/neuromedin $\mathrm{N}$ mRNA in the rat preoptic area. Journal of Comparative Neurology 311 84-96.

Allen LS \& Gorski RA 1992 Sexual orientation and the size of the anterior commissure in the human brain. PNAS 89 7199-7202.

Amateau SK \& McCarthy MM 2004 Induction of PGE2 by estradiol mediates developmental masculinization of sex behavior. Nature Neuroscience 7 643-650.

Archer J 1975 Rodent sex differences in emotional and related behavior. Behavioral Biology 14 451-479.

Arnold AP \& Gorski RA 1984 Gonadal steroid induction of structural sex differences in the central nervous system. Annual Review of Neuroscience 7 413-442.

Arnold AP, Xu J, Grisham W, Chen X, Kim Y-H \& Itoh Y 2004 Sex chromosomes and brain sexual differentiation. Endocrinology 145 1057-1062.

Auger AP 2004 Steroid receptor control of reproductive behavior. Hormones and Behavior 45 168-172.

Auger AP, Perrot-Sinal TS \& McCarthy MM 2001 Excitatory versus inhibitory GABA as a divergence point in steroid-mediated sexual differentiation of the brain. PNAS 98 8059-8064.

Aydogan M \& Barlas N 2006 Effects of maternal 4-tert-octylphhenol exposure on the reproductive tract of male rats at adulthood. Reproductive Toxicology Reproductive Toxicology 22 455-460.

Barfield RJ 1984 Reproductive hormones and aggressive behavior. Progress in Clinical and Biological Research 169 105-134.

Barraclough CA 1966 Modifications in the CNS regulation of reproduction after exposure of prepubertal rats to steroid hormones. Recent Progress in Hormone Research 22 503-539.

Baum MJ 2003 Activational and organizational effects of estradiol on male behavioural neuroendocrine function. Scandinavian Journal of Psychology 44 213-220.

Bay K, Asklund C, Skakkebaek NE \& Andersson A-M 2006 Testicular dysgenesis syndrome: possible role of endocrine disrupters. Best Practice \& Research Clinical Endocrinology and Metabolism 20 77-90.

Beatty WW 1979 Gonadal hormones and sex differences in nonreproductive behaviors in rodents: organizational and activational influences. Hormones and Behavior 12 112-163.

Bentvelsen FM, Brinkmann AO, van der Schoot P, van der Linden JETM, van der Kwast TH, Boersma WJA, Schroder FH \& Nijman JM 1995 Developmental pattern and regulation by androgens of androgen receptor expression in the urinogenital tract of the rat. Molecular and Cellular Endocrinology 113 245-253.

Beyer D, Kerlin S \& Diamond M 2005 Prenatal exposure to diethylstilbestrol(DES) in males and gender-related disorders:results from a 5-year study. Proceedings of the International Behavioral Development Symposium. Minot State University, North Dakota. USA.

Bimonte HA, Fitch RH \& Denenberg VH 2000 Neonatal estrogen prevents normal callosal responsiveness to estradiol in adulthood. Developmental Brain Research 122 149-155.

Blizard D \& Denef C 1973 Neonatal androgen effects on open-field activity and sexual behavior in the female rat: the modifying influence of ovarian secretions during development. Physiology and Behavior 11 65-69.

Bloch GJ \& Mills R 1995 Prepubertal testosterone treatment of neonatally gonadectomized male rats: defeminization and masculinization of behavioral and endocrine function in adulthood. Neuroscience and Biobehavioral Reviews 19 187-200.

Bloch GJ, Mills R \& Gale S 1995 Prepubertal testosterone treatment of female rats: defeminization of behavioural and endocrine function in adulthood. Neuroscience and Biobehavioral Reviews 19 177-186.
Borisova NA, Proshlyakova EV, Sapronova AY \& Ugrumov MV 1996 Androgen-dependent sex differences in the hypothalamic serotonergic system. European Journal of Endocrinology 134 232-235.

Borch J, Axelstad M, Vinggaard AM \& Dalgaard M 2006 Diisobutyl phthalate has comparable anti-androgenic effects to di- $n$-butyl phthalate in fetal rat testis. Toxicology Letters 163 183-190.

Bowles J \& Koopman P 2001 New clues to the puzzle of mammalian sex determination. Genome Biology 2 10251-10254.

Breedlove MS 1994 Sexual differentiation of the human nervous system. Annual Review of Neuroscience 45 389-418.

Breedlove MS 1997 Neonatal androgen and estrogen treatments masculinize the size of motoneurons in the rat spinal nucleus of the bulbocavernosus. Cellular and Molecular Neurobiology 17 687-714.

Brevini TA, Zanetto SB \& Cillo F 2005 Effects of endocrine disruptors on developmental and reproductive functions. Current Drug Targets. Immune, Endocrine and Metabolic Disorders 5 1-10.

Byskov AG 1986 Differentiation of mammalian embryonic gonad. Physiological Reviews 66 71-117.

Byskov AG, Baltsen M \& Anderson CY 1998 Meiosis-activating sterols: background, discovery and possible use. Journal of Molecular Medicine 76 818-823.

Canick JA, Tobet SA, Baum MJ, Vaccaro DE, Ryan KJ, Leeman SE \& Fox TO 1987 Studies on the role of catecholamines in the regulation of the developmental pattern of hypothalamic aromatase. Steroids 50 509-521.

Carlsen E, Giwercman A, Keiding N \& Skakkebaek NE 1992 Evidence for the decreasing quality of semen during the past 50 years. British Medical Journal 305 609-613.

Carrer HF \& Cambiasso MJ 2002 Sexual differentiation of the brain: genes, estrogen and neurotrophic factors. Cellular and Molecular Neurobiology 22 479-500.

Carruth LL, Reisert I \& Arnold AP 2002 Sex chromosome genes directly affect brain sexual differentiation. Nature Neuroscience 5 933-934.

Chappel SC, Resko JA, Norman RL \& Spies HG 1981 Studies in rhesus monkeys on the site where estrogen inhibits gonadotropins: delivery of $17 \beta$ beta-estradiol to the hypothalamus and pituitary gland. Journal of Clinical Endocrinology and Metabolism 52 1-8.

Chan W-Y \& Rennert OM 2002 Molecular aspects of sex differentiation. Current Molecular Medicine 2 25-37.

Clarkson J \& Herbison AE 2006 Postnatal development of kisspeptin neurons in mouse hypothalamus; sexual dimorphism and projections to gonadotropin-releasing hormone neurons. Endocrinology 147 5817-5825

Cohen-Bendahan CCC, Buitelaar JK, Van Goozen SHM \& CohenKettenis PT 2004 Prenatal exposure to testosterone and functional cerebral lateralization: a study in same-sex and opposite-sex twin girls. Psychoneuroendocrinology 29 911-916.

Cohen-Bendahan CCC, Van de Beek C \& Berenbaum SA 2005 Prenatal sex hormone effects and adult sex-typed behavior: methods and findings. Neuroscience and Biobehavioral Reviews 29 353-384.

Colborn T, vom Saal FS \& Soto AM 1993 Developmental effects of endocrine-disrupting chemicals in wildlife and humans. Environmental Health Perspectives 10 378-384.

Cowburn PJ \& Payne AP 1994 Androgens and indoleamines interact to control sexual dimorphisms in the rat spinal cord. Neuroscience Letters 169 101-104.

Dakin CL, Wilson CA, Kalló, I, Coen CW \& Davies DC Neonatal stimulation of 5-HT2 receptors reduces androgen receptor expression in the sexually dimorphic rat AVPV and SDN-POA. [in press].

Davies DC, Woods L, Dakin CL, Cope C \& Wilson CA 2004 Sex differences in the size and axonal content of the rat anterior commissure. Hormones and Behavior 4687.

Davis AM, Grattan DR, Selmanoff M \& McCarthy MM 1996 Sex differences in glutamic acid decarboxylase mRNA in neonatal rat brain: implications for sexual differentiation. Hormones and Behavior 30 538-552.

Davis EC, Shryne JE \& Gorski RA 1995 A revised critical period for the sexual differentiation of the sexually dimorphic nucleus of the preoptic area in the rat. Neuroendocrinology 62 579-585. 
Davis M, Ward SC, Selmanoff M, Herbison AE \& McCarthy MM 1999 Developmental sex differences in aminao acid neurotransmitter levels in hypothalamic and limbic areas of rat brain. Neuroscience 90 1471-1482.

Dessì-Fulgheri F, Porrini S \& Farabollini F 2002 Effects of perinatal exposure to Bisphenol A on play behavor of female and male juvenile rats. Environmental Health Perspectives 110 (Suppl 3) 403-407.

De Vries GJ, Rissman EF, Simerly RB, Yang L-Y, Scordalakes EM, Auger CJ, Swain A, Lovell-Badge R, Burgoyne PS \& Arnold APA 2002 Model system for study of sex chromosome effects on sexually dimorphic neural and behavioural traits. Journal of Neuroscience 22 9005-9014.

De Vries GJ \& Panzica GC 2006 Sexual differentiation of central vasopressin and vasotocin systems in vertebrates: different mechanisms, similar endpoints. Neuroscience 138 947-955.

De Vries GJ, Buijs RM \& Swaab DF 1981 Ontonogy of the vasopressinergic neurones of the suprachiasmatic nucleus and their extra-hypothalamic projections in the rat brain-presence of a sex difference in the lateral septum. Brain Research 218 67-78.

Demarest KT, McKay DW, Riegle GD \& Moore KE 1981 Sexual differences in tuberoinfundibular dopamine nerve action induced by neonatal androgen exposure. Neuroendocrinology 32 108-113.

Dewing P, Shi T, Horvath S \& Vilain E 2003 Sexually dimorphic gene expression in mouse brain precedes gonadal differentiation. Molecular Brain Research 118 82-90.

Dewing P, Chiang CWK, Sinchak K, Sim H, Fernagut P-O, Kelly S, Chesselet M-F, Micevych PE, Albrecht KH, Harley VR et al. 2006 Direct regulation of adult brain function by the male-specific factor SRY. Current Biology 16 415-420.

Diaz DR, Fleming DE \& Rhees RW 1995 The hormone-sensitive early postnatal periods for sexual differentiation of feminine behavior and luteinizing hormone secretion in male and female rats. Developmental Brain Research 86 227-232.

Diamond MC 1991 Hormonal effects on the development of cerebral lateralization. Psychoneuroendocrinology 16 121-129.

Diez d'Aux RC \& Pearson Murphy BE 1974 Androgens in the human fetus. Journal of Steroid Biochemistry 5 207-210.

Diez-Guerra FJ, Bicknell RJ, Mansfield S, Emson PC \& Dyer RG 1987 Effect of neonatal testosterone upon opioid receptors and the content of beta-endorphin, neuropeptide $Y$ and neurotensin in the medial preoptic and the mediobasal hypothalamic areas of the rat brain. Brain Research 424 225-230.

Dixson AF, Brown GR \& Nevison CM 1998 Developmental significance of the post natal testosterone surge in male primates. In Males, Females and Behavior: Toward Biological Understanding, Eds L Ellis \& L Ebertz. Westport USA: Praeger.

Döhler KD 1991 The pre- and postnatal influences of hormones and neurotransmitters on sexual differentiation of the mammalian hypothalamus. International Review of Cytology 131 1-57.

Döhler KD, Hancke JL, Srivastava SS, Hofmann C, Shryne JE \& Gorski RA 1984 Participation of estrogens in female sexual differentiation of the brain; neuroanatomical, neuroendocrine and behavioral evidence. Progress in Brain Research 61 99-117.

DonCarlos LL, McAbee M, Ramer-Quinn DS \& Stancik DM 1995 Estrogen receptor mRNA levels in the preoptic area of neonatal rats are responsive to hormone manipulation. Developmental Brain Research 84 253-260.

Dorner G, Docke F, Gotz F, Rohde W, Stahl F \& Tonjes R 1987 Sexual differentiation of gonadotrophin secretion, sexual orientation and gender role behavior. Journal of Steroid Biochemistry 27 1081-1087.

Ehrhardt AA, Meyer-Bahlburg HF, Rosen LR, Feldman JF, Veridiano NP, Zimmermann I \& McEwen BS 1985 Sexual orientation after prenatal exposure to exogenous estrogen. Archives of Sexual Behavior 14 57-77.

El-Gehani F, Zhang F-P, Pakarinen P, Rannikko A \& Huhtaniemi I 1998a Gonadotropin-independent regulation of steroidogenesis in the fetal rat testis. Biology of Reproduction 58 116-123.
El-Gehani F, Tena-Sempere M \& Huhtaniemi I 1998b Vasoactive intestinal peptide is an important endocrine regulatory factor of fetal rat testicular steroidogenesis. Endocrinology 139 1474-1480.

El-Gehani F, Tena-Sempere M \& Huhtaniemi I 2000 Evidence that pituitary adenylate cyclase-activating polypeptide is a potent regulator of fetal rat testicular steroidogenesis. Biology of Reproduction 63 1482-1489.

El-Gehani F, Tena-Sempere M, Ruskoaho H \& Huhtaniemi I 2001 Natriuretic peptides stimulate steroidogenesis in the fetal rat testis. Biology of Reproducton 65 595-600.

Falkenstein E, Tillmann H-C, Christ M, Feuring M \& Wehling M 2000 Multiple actions of steroid hormones - a focus on rapid, nongenomic effects. Pharmacological Reviews 52 513-555.

Farabollini F, Porrini S \& Dessì-Fulgheri F 1999 Perinatal exposure to the estrogenic pollutant Bisphenol A affects behavior in male and female rats. Pharmacology Biochemistry and Behavior 64 687-694.

Farabollini F, Porrini S, Della Seta D, Bianchi F \& Dessì-Fulgheri F 2002 Effects of perinatal exposure to Bisphenol A on sociosexual behavor of female and male rats. Environmental Health Perspectives 110 (Supplement 3) 409-414.

Fernandez-Galaz MC, Parducz A, Naftolin F, Torres-Aleman I \& Garcia-Segura LM 1997 Interaction of gonadal steroids and growth factors in brain sex differentiation. Biomedical Reviews 7 67-74.

Fink G \& Henderson SR 1977 Steroids and pituitary responsiveness in female, androgenized female and male rats. Journal of Endocrinology 73 157-164.

Fink G, Rosie R, Sheward WJ, Thomson E \& Wilson H 1991 Steroid control of central neuronal interactions and function. Journal of Steroid Biochemical Molecular Biology 40 123-132.

Fleming A \& Vilain E 2004 The endless quest for sex determination genes. Clinical Genetics 67 15-25.

Foecking EM, Szabo M, Schwartz NB \& Levine JE 2005 Neuroendocrine consequences of prenatal androgen exposure in the female rat: absence of luteinizing hormone surges, suppression of progesterone receptor gene expression, and acceleration of the gonadotropinreleasing hormone pulse generator. Biology of Reproduction $\mathbf{7 2}$ 1475-1483.

Forest MG 1979 Plasma androgens (testosterone and 4-androstenedione) and 17-hydroxyprogesterone in the neonatal, prepubertal and peripubertal periods in the human and the rat: differences between species. Journal of Steroid Biochemistry 11 543-548.

Forest MG, de Peretti E \& Bertrand J 1980 Testicular and adrenal androgens and their binding to plasma proteins in the perinatal period: developmental patterns of plasma testosterone, 4 -androstenedione, dehydroepiandrosterone and its sulfate in premature and small for date infants as compared with that of fullterm infants. Journal of Steroid Biochemistry 12 25-36.

Forger NG 2006 Cell death and sexual differentiation of the nervous system. Neuroscience 138 929-938.

Forger NG, Rosen GJ, Waters EM, Jacob D, Simerly RB \& de Vries GJ 2004 Deletion of Bax differences in the mouse forebrain. PNAS 101 13666-13671.

Foster PMD 2006 Disruption of reproductive development in male rat offspring following in utero exposure to phthalate esters. International Journal of Andrology 29 140-147.

Garcia-Falgueras A, Pinos H, Collado P, Pasaro E, Fernadez R, Jordan CL, Segovia S \& Guillamón A 2005 The role of the androgen receptor in CNS masculinization. Brain Research 1035 13-23.

Gadea M, Gómez C, González-Bono E, Salvador A \& Espert R 2003 Salivary testosterone is related to both handedness and degree of linguistic lateralization in normal women. Psychoneuroendocrinology 28 274-287.

Ge F, Hammer RP Jr \& Tobet SA 1993 Ontogeny of leu-enkephalin and beta-endorphin innervation of the preoptic area in male and female rats. Developmental Brain Research 73 273-281.

Giulian D, Pohorecky LA \& McEwen BS 1973 Effects of gonadal steroids upon 5-hydroxytryptamine levels in the neonatal rat. Endocrinology 93 1329-1335. 
Goldfoot DA \& Van Der Werff Ten Bosch JJ 1975 Mounting behavior of female guinea pigs after prenatal and adult administration of the propionates of testosterone, dihydrotestosterone and androstenediol. Hormones and Behavior 6 139-148.

Gonzales GF, Ortega JG \& Salazar M 2000 Effect of neonatal administration of an antidopaminergic drug (metoclopramide) on sexual behavior of male rats. Archives of Andrology 45 137-142.

Goodman RL 1978 The site of positive feedback action of estradiol in the rat. Endocrinology 102 151-159.

Gorski RA, Gordon JH, Shryne JE \& Southam AM 1978 Evidence for a morphological sex difference within the medial preoptic area of the rat brain. Brain Research 148 333-346.

Goy RW \& Resko JA 1972 Gonadal hormones and behavior of normal and pseudohermaphroditic nonhuman female primates. Recent Progress in Hormone Research 28 707-733.

Gray LE Jr, Ostby J, Monosson E \& Kelce WR 1999 Environmental antiandrogens: low doses of the fungicide vinclozolin alter sexual differentition of the male rat. Toxicology and Industrial Health $\mathbf{1 5}$ 48-64.

Gray LE Jr, Wilson VS, Stoker T, Lambright C, Furr J, Noriega N, Howdeshell K, Ankley GT \& Guillette L 2006 Adverse effects of environmental antiandrogens and androgens on reproductive development in mammals. International Journal of Andrology 29 96-104.

Greco TL, Duello TM \& Gorski J 1993 Estrogen receptors, estradiol, and diethylstilbestrol in early development: the mouse as a model for the study of estrogen receptors and estrogen sensitivity in embryonic development of male and female reproductive tracts. Endocrine Reviews 14 59-71.

Grumbach MM \& Auchus RJ 1999 Estrogen: consequences and implications of human mutations in synthesis and action. Journal of Clinical Endocrinology \& Metabolism 84 4677-4694.

Gu GB \& Simerly RB 1997 Projections of the sexually dimorphic anteroventral periventricular nucleus in the female rat. Journal of Comparative Neurology 384 142-164.

Guo W, Burris TP \& McCabe ER 1995 Expression of DAX-1, the gene responsible for $\mathrm{X}$-linked adrenal hypolasia congenita and hypogonadotropic hypogonadism, in the hypothalamic-pituitary-adrenal/gonadal axis. Biochemical and Molecular Medicine 56 8-13.

Henderson RG, Brown AE \& Tobet SA 1999 Sex differences in cell migration in the preoptic area/anterior hypothalamus of mice. International Journal of Neurobiology 41 252-266.

Herbison AE 1992 Identification of a sexually dimorphic neural population immunoreactive for calcitonin gene-related peptide (CGRP) in the rat medial preoptic area. Brain Research 591 289-295.

Herbison AE 1998 Multimodal influence of estrogen upon gonadotropin-releasing hormone neurons. Endocrine Reviews 19 302-330.

Hilsher B, Hilscher W, Bulthoff-Ohnolz B, Kramer U, Birke A, Pelzer H \& Gauss G 1974 Kinetics of gametogenesis. I. Comparative histological and autoradiographic studies of oocytes and transitional prospermatogonia during oogenesis and prespermatogenesis. Cell and Tissue Research 154 443-470.

Hines M \& Sandberg EC 1996 Sexual differentiation of cognitive abilities in women exposed to diethylstilbestrol (DES) prenatally. Hormones and Behavior 30 354-363.

Hoffman GE, Dohanics J, Watson RE Jr \& Wiegand SJ 1996 The hypothalamic ventromedial nucleus sends a met-encephalin projection to the preoptic area's periventricular zone in the female rat. Molecular Brain Research 36 201-210.

Hood SC \& Schwartz NB 2000 Sex differences in serum luteinizing hormone post-gonadectomy in the rat: role of gamma-aminobutyric acid-ergic inhibition. Endocrine 12 35-40.

Hoyer PB 2001 Reproductive toxicology: current and future directions. Biochemical Pharmacology 62 1557-1564.

Hull EM, Nishita JK, Bitran D \& Dalterio S 1984 Perinatal dopaminerelated drugs demasculinize rats. Science 224 1011-1013.

Huhtaniemi I \& Pelliniemi LJ 1992 Fetal Leydig cells: cellular origin, morphology, life span, and special functional features. Proceedings of the Society for Experimental Biological Medicine 201 125-140.
Hutchison JB 1997 Gender-specific steroid metabolism in neural differentiation. Cellular and Molecular Neurobiology 17 603-626.

Ikeda Y, Swin A, Weber TJ, Hentges KE, Zanaria E, Lalli E, Tamai KT, Sassone-Corsi P, Lovell-Badge R, Camerino G et al. 1996 Steroidogenic factor 1 and Dax- 1 colocalize in multiple cell lineages: potential links in endocrine development. Molecular Endocrinology 10 1261-1272.

Ikeda Y, Nagai A, Ikeda M-A \& Hayashi S 2003 Sexually dimorphic and estrogen-dependent expression of estrogen receptor $\beta$ in the ventromedial hypothlamus during rat postnatal development. Endocrinology 144 5098-5104.

Jarzab B \& Döhler KD 1984 Serotonergic influences on sexual differentiation of the rat brain. Progress in Brain Research $\mathbf{6 1}$ 119-126.

Jarzab B, Sickmoller PM, Geerlings H \& Döhler KD 1987 Postnatal treatment of rats with adrenergic receptor agonists or antagonists influences differentiation of sexual behaviour. Hormones and Behavior 21 478-492.

Jarzab B, Kaminski M, Gubala E, Achtelik W, Wagiel J \& Döhler KD 1990 Postnatal treatment of rats with ß2-adrenergic agonist salbutamol influences the volume of the sexually dimorphic nucleus in the preoptic area. Brain Research 516 257-262.

Johnston HM, Payne AP \& Gilmore DP 1992 Perinatal exposure to morphine affects adult sexual behavior of the male golden hamster. Pharmacology, Biochemistry and Behavior 42 41-44.

Joseph R, Hess S \& Birecree E 1978 Effects of hormone manipulations and exploration on sex differences in maze learning. Behavioral Biology 24 364-377.

Jost A, Vigier B, Prepin J \& Perchellett JP 1973 Studies on sex differentiation in mammals. Recent Progress in Hormone Research 29 1-41.

Kaipia A, Toppari J, Huhtaniemi I \& Paranko J 1994 Sex difference in the action of activin-A on cell proliferation of differentiating rat gonad. Endocrinology 134 2165-2170.

Kansaku K \& Kitazawa S 2001 Imaging studies on sex differences in the lateralization of language. Neuroscience Research 41 333-337.

Karsch FJ, Dierschke DJ \& Knobil E 1973 Sexual differentiation of pituitary function: apparent difference between primates and rodents. Science 179 484-486.

Kawashima S \& Takagi K 1994 Role of sex steroids on the survival, neuritic outgrowth of neurons, and dopamine neurons in cultured preoptic area and hypothalamus. Hormones and Behavior 28 305-312.

Kikuyama S 1962 Inhibition of induction of persistent estrus by chlorpromazine. Annotationes Zoologicae Japonenses 35 6-11.

Kitajewski J \& Sassoon D 2000 The emergence of molecular gynaecology: homeobox and Wnt genes in the female reproductive tract. BioEssays 22 902-910.

Koopman P 2001 Sry, Sox9 and mammalian sex determination. In Genes and Mechanisms in Vertebrate Sex Determination, pp 25-56. Eds G Scherer \& M Schmid. Basel: Birkhäuser Verlag.

Koopman P 2005 Sex determination: a tale of two Sox genes. Trends in Genetics 21 367-370.

Koopman P, Bullejos M \& Bowles J 2001 Regulation of male sexual development by Sry and Sox9. Journal of Experimental Zoology 290 463-474.

Kouki T, Kishitake M, Okamoto M, Oosuka I, Takebe M \& Yamanouchi K 2003 Effects of neonatal treatment with phytoestrogens, genistein and daidzein on sex difference in female rat brain function: estrous cycle and lordosis. Hormones and Behavior 44 140-145.

Kubo K, Arai O, Omura M, Watanabe R, Ogata R \& Aou S 2003 Low dose effects of bisphenol A on sexual differentiation of the brain and behavior in rats. Neuroscience Research 45 345-356.

Kudwa AE, Michopoulos V, Gatewood JD \& Rissman EF 2006 Roles of estrogen receptors $\alpha$ and $\beta$ in differentiation of mouse sexual behavior. Neuroscience 138 921-928.

Kuhnemann S, Brown TJ, Hochberg RB \& MacLusky NJ 1995 Sexual differentiation of oestrogen receptor concentrations in the rat brain: effects of neonatal testosterone exposure. Brain Research 691 $229-234$ 
Ladosky W \& Gaziri LC 1970 Brain serotonin and sexual differentiation of the nervous system. Neuroendocrinology 6 168-114.

Lasco MS, Jordan TJ, Edgar MA, Petito CK \& Byne W 2002 A lack of dimorphism of sex or sexual orientation in the anterior commissure. Brain Research 936 95-98.

Leclercq P \& Herbison AE 1996 Sexually dimorphic expression of calcitonin gene-related peptide (CGRP) immunoreactivity by rat mediobasal hypothalamic neurons. Journal of Comparative Neurology 367 444-453.

Lephart ED, Call SB, Rhees RW, Jacobson NA, Scott Weber K, Bledsoe J \& Teuscher C 2001 Neuroendocrine regulation of sexually dimorphic brain structure and associated sexual behavior in male rats is genetically controlled. Biology of Reproduction 64 571-578.

Lesage J, Bernet F, Montel V \& Dupouy JP 1996 Hypothalamic metabolism of neurotransmitters (serotonin, norepinephrine, dopamine) and NPY, and gonadal and adrenal activities, during the early postnatal period in the rat. Neurochemistry Research 21 87-96.

Levine JE, Norman RL, Gliessman PM, Oyama TT, Bangsberg DR \& Spies HG 1985 In vivo gonadotropin-releasing hormone release and serum luteinizing hormone measurements in ovariectomized, estrogen-treated rhesus macaques. Endocrinology 117 711-721.

Levine JE 1997 New concepts of the neuroendocrine regulation of gonadotropin surges in rats. Biology of Reproduction 56 293-302.

Levy JR, Faber KA, Ayyash L \& Hughes CL Jr 1995 The effect of prenatal exposure to the phytoestrogen genistein on sexual differentiation in rats. Proceedings of the Society of Experimental Biology and Medicine 208 60-66.

Lippa RA 2006 Finger lengths, 2D:4D ratios, and their relation to gender-related personality traits and the Big Five. Biological Psychology 71 116-121.

Lira SA, Phipps DW Jr \& Sarkar DK 1986 Loss of estradiol-positive feedback action on $\mathrm{LH}$ release during prepubertal period in rats treated postnatally with an opiate antagonist. Neuroendocrinology 44 331-337.

Liaw JJ \& Barraclough CA 1993 Pituitary gland responsiveness to LHRH and LHRH neuronal responsiveness to excitatory stimuli are severely impaired in female rats treated neonatally with high doses of androgen. Brain Research 607 233-240.

Lish JD, Ehrhardt AA, Meyer-Bahlburg HF, Rosen LR, Gruen S \& Veridianao NP 1991 Gender-related behavior development in females exposed to diethystilbestrol (DES) in utero: an attempted replication. Journal of the American Academy of Child and Adolescent Psychiatry 30 29-37.

Loffler KA \& Koopman P 2002 Charting the course of ovarian development in vertebrates. International Journal of Developmental Biology 46 503-510.

Loke DF, Ratnam SS \& Goh HH 1992 Long-term oestrogen priming on basal and oestradiol-induced release of luteinizsng hormone secretion in male rats. Annals of the Academy of Medicine of Singapore 21 765-768.

MacLusky NJ \& Naftolin F 1981 Sexual differentiation of the nervous system. Science 211 1294-1303.

Madeira MD, Ferreira-Silva L \& Paula Barbosa MM 2001 Influence of sex and estrus cycle on the sexual dimorphisms of the hypothalamic ventromedial nucleus: stereological evaluation and Golgi study. Journal of Comparative Neurology 432 329-345.

Markey CM, Coombs MA, Sonnenschein C \& Soto AM 2003 Mammalian development in a changing environment: exposure to endocrine disruptors reveals the developmental plasticity of steroidhormone target organs. Evolution and Development 5 67-75.

Marshall Graves JA 2000 Human Y chromosome, sex determination, and spermatogenesis - a feminist view. Biology of Reproduction $\mathbf{6 3}$ 667-676.

Masutomi N, Shibutani M, Takagi H, Uneyama C, Takahashi N \& Hirose M 2003 Impact of dietary exposure to methoxychlor, genistein, or diisononyl phthalate during the perinatal period on the development of the rat endocrine/reproductive systems in later life. Toxicology 192 149-170.
Matsumoto A \& Arai Y 1980 Sexual dimorphism in the 'wiring pattern' in the hypothalamic nucleus and its modification by neonatal hormonal environment. Brain Research 190 238-242.

Matsumoto A \& Arai Y 1997 Sexual differentiation of neuronal circuitry in the neuroendocrine hypothalamus. Biomedical Reviews 7 5-15.

Mattson MP 1988 Neurotransmitters in the regulation of neuronal cytoarchitecture. Brain Research Reviews 13 179-212.

Maxson SC 1997 Sex differences in genetic mechanisms for mammalian brain and behavior. Biomedical Reviews 7 85-90.

Mayer A, Mosler G, Just W, Pilgrim C \& Reisert I 2000 Developmental profile of Sry transcripts in mouse brain. Neurogenetics 3 25-30.

Mayer A, Lahr G, Swaab DF, Pilgrim C \& Reisert I 1998 The Y-chromosomal genes SRY and ZFY are transcribed in adult human brain. Neurogenetics 1 281-288.

McAbee MD \& DonCarlos LL 1999 Estrogen, but not androgens, regulates androgen receptor messenger ribonucleic acid expression in the developing male rat forebrain. Endocrinology $\mathbf{1 4 0}$ 3674-3681.

McCarthy MM, Amateau SK \& Mong JA 2002a Steroid modulation of astrocytes in the neonatal brain: implications for adult reproductive function. Biology of Reproduction 67 691-698.

McCarthy MM, Auger AP \& Perrot-Sinal TS 2002 $b$ Getting excited about GABA and sex differences in the brain. Trends in Neurosciences 25 307-312.

McFadden D, Loehlin JC, Breedlove SM, Lippa RA, Manning JT \& Rahman Q 2005 A re-analysis of five studies on sexual orientation and the relative length of the 2 nd and 4 th fingers (the $2 \mathrm{D}: 4 \mathrm{D}$ ratio). Archives of Sexual Behavior 34 341-356.

Meaney MJ 1989 The sexual differentiation of social play. Psychiatry of Development 7 247-261.

Meaney MJ, Stewart J, Poulin P \& McEwen BS 1983 Sexual differentiation of social play in neonatal rat pups is mediated by the neonatal androgen-receptor system. Neuroendocrinology 37 85-90.

Melnikova V, Orosco M, Cala A, Sapronova A, Gainetdinov R, Delhaye-Bouchaud N, Nicolaidis S, Rayevsky K \& Ugrumov M 1999 Dopamine turnover in the mediobasal hypothalamus in rat. Neuroscience 89 235-241.

Mhyre AJ \& Dorsa DM 2006 Estrogen activates rapid signalling in the brain: role of estrogen receptor $\alpha$ and estrogen receptor $\beta$ in neurons and glia. Neuroscience 138 851-858.

Micevych PE, Park SS, Akesson TR \& Elde R 1987 Distribution of Cholecystokinin-immunoreactive cell bodies in the male and female rat: I. Hypothalamus. Journal of Comparative Neurology 255 124-136.

Mitsushima D, \& Kimura F 2003 Sexual dimorphism in the GABAergic control of gonadotropin release in intact rats. Neuroscience Research 46 399-405.

Mittwoch U 2000 Genetics of sex determination: exceptions that prove the rule. Molecular Genetics and Metabolism 71 405-410.

Mong JA \& Blutstein T 2006 Estradiol modulation of astrocytic form and function: implications for hormaonal control of synaptic communication. Neuroscience 138 967-975.

Murray JF, Dakin CL, Siddiqui A, Pellatt LJ, Ahmed S, Ormerod LJA, Swann AV, Davies DC \& Wilson CA 2004 Neonatal 5HT activity antagonizes the masculinizing effect of testosterone on the luteinizing hormone release response to gonadal steroids and on brain structures in rats. European Journal of Neuroscience 19 387-395.

Naftolin F, Keefe D, Apa R, Palumbo A \& 1991 The apparent paradox of sexual differentiation of the brain. In Achievements in Gynecology 1989-1990. Contributions in Gynecology and Obstetrics, pp 24-32. Ed. S Mancuso. Basel: Karger.

Nakai Y, Plant TM, Hess DL, Keogh EJ \& Knobil E 1978 On the sites of the negative and positive feedback actions of estradiol in the control of gonadotropin secretion in the Rhesus monkey. Endocrinology 102 1008-1014. 
Nakano H, Fawcett CP \& McCann SM 1976 Enzymatic dissociation and short-term culture of isolated rat anterior pituitary cells for studies on the control of hormone secretion. Endocrinology 98 278-288.

Nance DM \& Gorski RA 1975 Neurohormonal determinants of sex differences in the hypothalamic regulation of feeding behavior and body weight in the rat. Pharmacology Biochemistry and Behavior 3 155-162.

Newbold RR 1993 Gender-related behaviour in women exposed to diethylstilboestrol. Environmental Health Perspectives 101 208-213.

Nishizuka M, Sumida H, Kano Y \& Arai Y 1993 Formation of neurons in the sexually dimorphic anteroventral paraventricular nucleus of the preoptic area of the rat: effects of prenatal treatment with testosterone propionate. Journal of Neuroendocrinology 5 569-573.

Noonan M, Smith MA, Kelleher K \& Sanfilippo MA 1998 Sex differences in anterior commissure size in the rat. Brain Research Bulletin 45 101-104.

Norman RL \& Spies HG 1986 Cyclic ovarian function in a male macque: additional evidence for a lack of sexual differentiation in the physiological mechanisms that regulate the cyclic release of gonadotropins in primates. Endocrinology 118 2608-2610.

Olesen KM, Jessen HM, Auger CJ \& Auger AP 2005 Dopaminergic activation of estrogen receptors in neonatal brain alters progestin receptor expression and juvenile social play behavior. Endocrinology 146 3705-3712.

Orikasa C, Kondo Y, Hayashi S, McEwen BS \& Sakuma Y 2002 Sexually dimorphic expression of estrogen receptor $\beta$ in the anteroventral periventricular nucleus of the rat preoptic area: implication in luteinizing hormone surge. PNAS 99 3306-3311.

Park SY \& Jameson JL 2005 Transcriptional regulation of gonadal development and differentiation. Endocrinology 146 1035-1042.

Patchev AV, Gotz F \& Rohde W 2004 Differential role of estrogen receptor isoforms in sex-specific brain organization. FASEB Journal 18 1568-1570.

Pei M, Matsuda K, Sakamoto H \& Kawata M 2006 Intrauterine proximity to male fetuses affects the morphology of the sexually dimorphic nucleus of the preoptic area of the rat brain. European Journal of Neuroscience 23 1234-1240.

Perrot-Sinal TS, Davis AM, Gregerson KA, Kao JPY \& McCarthy MM 2001 Estradiol enhances excitatory gammabutyric acid-mediated calcium signalling in neonatal hypothalamic neurons. Endocrinology 142 2238-2243.

Petrusz P \& Flerko B 1965 On the mechanism of sexual differentiation of the hypothalamus. Acta Biologica Academia Scientifica Hungarica 16 169-173.

Pfaff D 1966 Morphological changes in the brains of adult male rats after neonatal castration. Journal of Endocrinology 36 415-426.

Pfeiffer CA 1936 Sexual differences of the hypophysis and their determination by the gonads. American Journal of Anatomy $\mathbf{5 8}$ 195-225.

Phoenix CH, Goy RW, Gerall AA \& Young WC 1959 Organizing action of prenatally administered testosterone proprionate on the tissues mediating mating behavior in the female guinea pig. Endocrinology 65 369-382.

Pocock VJ, Sales GD, Wilson CA \& Milligan SR 2002 Effects of perinatal octylphenol on ultrasound vocalisation behavior and reproductive physiology in rats. Physiology and Behavior 76 645-653.

Power RF, Mani SK, Codina J, Connelly OM \& O'Malley BW 1991 Dopaminergic and ligand-independent activation of steroid hormone receptors. Science 254 1636-1639.

Quadros PS, Goldstein AYN, De Vries GJ \& Wagner CK 2002a Regulation of sex differences in progesterone receptor expression in the medial preoptic nucleus of postnatal rats. Journal of Neuroendocrinology 14 761-767.

Quadros PS, Pfau JL, Goldstein AYN, De Vries GJ \& Wagner C 2002b Sex differences in progesterone receptor expression: a potential mechanism for estradiol-mediated sexual differentiation. Endocrinology 143 3727-3739.

Raisman G \& Field PM 1971 Sexual dimorphism in the preoptic area of the rat. Science 173 731-733.
Raum WJ \& Swerdloff RS 1981 The role of hypothalamic adrenergic receptors in preventing testosterone-induced androgenization in the male rat brain. Endocrinology 109 273-278.

Raum WJ, Marcano M \& Swerdloff RS 1984 Nuclear accumulation of estradiol derived from the aromatization of testosterone is inhibited by hypothalamic beta-receptor stimulation in the neonatal female rat. Biology of Reproduction 30 388-396.

Reinisch JM, Ziemba-Davis M \& Sanders SA 1991 Hormonal contibutions to sexually dimorphic behaviorl development in humans. Psychoneuroendocrinology 16 213-278.

Reinisch JM \& Sanders SA 1992 Effects of prenatal exposure to diethylstilbestrol (DES) on hemispheric laterality and spattial ability in human males. Hormones and Behavior 26 62-75.

Reisert I \& Pilgrim C 1991 Sexual differentiation of monoaminergic neurons - genetic or epigenetic? Trends in Neurosciences $\mathbf{1 4}$ 468-473.

Rey R, Lukas-Croisier C, Lasala C \& Bedecarrás P 2003 AMH/MIS: what we know about the gene, the protein and its regulation. Molecular and Cellular Endocrinology 211 21-31.

Reznikov AG \& Nosenko ND 1987 Prevention of the anovulatory syndrome and testosterone-induced rise in catecholamine level in the hypothalamus of newborn rats with steroid aromatase inhibitors. Experimental and Clinical Endocrinology 90 185-190.

Reznikov AG \& Nosenko ND 1996 Early postnatal changes in sexual dimorphism of catecholamine and indoleamine content in the brain of prenatally stressed rats. Neuroscience $\mathbf{7 0}$ 547-551.

Reznikov AG, Nosenko ND \& Tarasenko LV 2004 Early postnatal effects of prenatal exposure to glucocorticoids on testosterone metabolism and biogenic monoamines in discrete neuroendocrine regions of the rat brain. Comparative Biochemistry and Physiology, Part C 138 169-175.

Reznikov AG, Nosenko ND \& Tarasenko LV 2005 Opioids are responsible for neurochemical feminization of the brain in prenatally stressed male rats. Neuroendocrinology Letters 26 35-38.

Rhees RW, Kirk BA, Sephton S \& Lephart ED 1997 Effects of prenatal testosterone on sexual behavior, reproductive morphology and LH secretion in the female rat. Developmental Neuroscience 19 430-437.

Rhees RW, Al-Saleh HN, Kinghorn EW, Fleming DE \& Lephart ED 1999 Relationship between sexual behavior and sexually dimorphic structures in the anterior hypothalamus in control and prenatally stressed male rats. Brain Research Bulletin 50 193-199.

Rhoda J, Corbier P \& Roffi J 1984 Gonadal steroid concentrations in serum and hypothalamus of the rat at birth: aromatization of testosterone to 17 beta-estradiol. Endocrinology 114 1754-1760.

Rilea SL, Roskos-Ewolsen B \& Boles D 2004 Sex differences in spatial ability: a lateralization of function approach. Brain and Cognition $\mathbf{5 6}$ 332-343.

Roberts VJ, Sawchenko PE \& Vale W 1991 Expression of inhibin/activin subunit messenger ribonucleic acids during rat embryogenesis. Endocrinology 128 3122-3129.

Romano GJ, Mobbs CV, Lauber A, Howells RD \& Pfaff DW 1990 Differential regulation of proenkephalin gene expression by estrogen in the ventromedial hypothalamus of male and female rats: implications for the molecular basis of a sexually differentiated behaviour. Brain Research 536 63-68.

Romeo RD 2003 Puberty: a period of both organizational and activational effects of steroid hormones on neurobehavioural development. Journal of Neuroendocrinology 15 1185-1192.

Rozman D 2000 Lanosterol 14 alpha-demethylase (CYP51)-a cholesterol biosynthetic enzyme involved in production of meiosis activating sterol in oocytes and testis - a minireview. Pflugers Archives 493 R56-R57.

Ryan BS \& Vandenbergh JG 2002 Intrauterine position effects. Neuroscience and Biobehavioral Reviews 26 665-678.

Safe S 2005 Clinical correlates of environmental endocrine disruptors. Trends in Endocrinology and Metabolism 16 139-144.

Sandberg DE, Meyer-Bahlburg HF, Rosen TS \& Johnson HL 1990 Effects of prenatal methadone exposure on sex-dimorphic behavior in early school-age children. Psychoneuroendocrinology 15 77-82. 
Sato T, Matsumoto T, Kawano H, Watanabe T, Uematsu Y, Sekine K, Fukuda T, Aihara K, Krust A, Yamada T et al. 2004 Brain masculinization requires androgen receptor function. PNAS 101 1673-1678.

Segarra AC, Acosta AM, González JL, Angulo JA \& McEwen BS 1998 Sex differences in estrogenic regulation of preproenkephalin mRNA levels in the medial preoptic area of prepubertal rats. Molecular Brain Research 60 133-139.

Segovia S, Guillamón A, del Cerro MCR, Ortega E, Pérez-Laso C, Rodriguez-Zafra M \& Beyer C 1999 The development of brain sex differences: a multisignaling process. Behavioural Brain Research 105 69-80.

Sharpe RM 2006 Pathways of endocrine disruption during male sexual differentiation and masculinisation. Best Practice \& Research: Clinical Endocrinology and Metabolism 20 91-110.

Silverman AJ, Livne I \& Witkin JM 1994 The gonadotropin-releasing hormone $(\mathrm{GnRH})$ neuronal systems: imunocytochemistry and in situ hybridization. In The Physiology of Reproduction, 2 edn, pp 1683-1709. Ed. J.D. Neill et al., New York: Raven Press.

Simerly RB, Swanson LW \& Gorski RA 1985a Reversal of the sexually dimorphic distribution of serotonin-immunoreactive fibers in the medial preoptic nucleus by treatment with perinatal androgen. Brain Research 340 91-98.

Simerly RB, Swanson LW \& Gorski RA 1985b The distribution of monoaminergic cells and fibers in a periventricular preoptic nucleus involved in the control of gonadotropin release: immunohistochemical evidence for a dopaminergic sexual dimorphism. Brain Research 330 55-64.

Simerly RB, Gorski RA \& Swanson LW 1986 Neurotransmitter specificity of cells and fibers in the medial preoptic nucleus: an immunohistochemical study in the rat. Journal of Comparative Neurology 246 343-363.

Simerly RB, McCall LD \& Watson SJ 1988 Distribution of opioid peptides in the preoptic region: immunohistochemical evidence for a steroid-sensitive enkephalin sexual dimorphism. Journal of Comparative Neurology 276 442-459.

Simerly RB, Zee MC, Pendleton JW, Lubahn DB \& Korach KS 1997 Estrogen receptor-dependent sexual differentiation of dopaminergic neurons in the preoptic region of the mouse. PNAS 94 14077-14082.

Simerly RB 2002 Wired for reproduction: organization and development of sexually dimorhpic circuits in the mammalian forebrain. Annual Review of Neuroscience 25 507-536.

Sinclair AH, Berta P, Palmer MS, Hawkins JR, Griffiths BL, Smith MJ, Foster JW, Frischauf AM, Lovell-Badge R \& Goodfellow PN 1990 A gene from the human sex-determining region encodes a protein with homology to a conserved DNAbinding motif. Nature 346 240-244.

Smith LL \& Hines M 2000 Language lateralization and handedness in women prenatally exposed to diethylstibestrol (DES). Psychoneuroendocrinology 25 497-512.

Spies HG \& Norman RL 1975 Interaction of estradiol and LHRH on LH release in Rhesus females: evidence for a neural site of action. Endocrinology 97 685-692.

Stavnezer AJ, McDowell CS, Hyde LA, Bimonte HA, Balogh SA, Hoplight BJ \& Denenberg VH 2000 Spatial ability of XY sex-reversed female mice. Behavioural Brain Research 112 135-143.

Steiner RA, Clifton DK, Spies HG \& Resko JA 1976 Sexual differentiation and feedback control of luteinizing hormone secretion in the rhesus monkey. Biology of Reproduction 15 206-212.

Stocco DM \& McPhaul MJ 2006 Physiology of teticular steroidogenesis. In Knobil and Neill's Physiology of Reproduction, 3 edn, pp 977-1016. Ed. JD Neill. New York: Elsevier Academic Press.

Sullivan SD \& Moenter SM 2004 Prenatal androgens alter GABAergic drive to gonadotropin-releasing hormone neurons: implications for a common fertility disorder. PNAS 101 7129-7134.

Swaab DF 2004 Sexual differentiation of the human brain: relevance for gender identity, transsexualism and sexual orientation. Gynecological Endocrinology 19 301-312.
Swaab DF, Chung WC, Kruijver FP, Hofman MA \& Hestiantoro A 2003 Sex differences in the hypothalamus in the different stages of human life. Neurobiology of Aging 1 (Supplement 1) S1-S16.

Takagi H, Shibutani M, Lee K-Y, Masutomi N, Fujita H, Inoue K, Mitsumori K \& Hirose M 2005 Impact of maternal dietary exposure to endocrine-acting chemicals on progesterone receptor expression in microdissected hypothalamic medial preoptic areas of rat offspring. Toxicology and Applied Pharmacology 208 $127-136$.

Tang LK \& Tang FY 1979 Sex difference in LH response to LHRH and DBcAMP and effect of $17 \beta$-estradiol. American Journal of Physiology 236 E216-E221.

Tin-Tin-Win-Shwe, Mitsushima D, Shinohara K \& Kimura F 2004 Sexual dimorphism of GABA release in the medial preoptic area and luteinizing hormone release in gonadectomized estrogen-primed rats. Neuroscience 127 243-250.

Titus-Ernstoff L, Perez K, Hatch EE, Troisi R, Palmer JR, Hartge P, Hyer M, Kaufman R, Adam E, Strohsnitter W et al. 2003 Psychosexual characteristics of men and women exposed prenatally to diethylstilbestrol. Epidemiology 14 155-160.

Tobet SA 2002 Genes controlling hypothalamic development and sexual differentiation. European Journal of Neuroscience $\mathbf{1 6}$ 373-362.

Urban JH, Bauer-Dantoin AC \& Levine JE 1993 Neuropeptide Y gene expression in the arcuate nucleus: sexual dimorphism and modulation by testosterone. Endocrinology 132 139-145.

Vathy I, Rimanoczy A, Eaton RC \& Katay L 1995 Sex dimorphic alterations in postnatal brain catecholamines after gestational morphine. Brain Research Bulletin 36 185-193.

Vidaeff AC \& Sever LE 2005 In utero exposure to environmental estrogens and male reproductive health: a systematic review of biological and epidemiologic evidence. Reproductive Toxicology 20 $5-20$.

Viger RS, Silversides DW \& Tremblay JJ 2005 New insights into the regulation of mammalian sex determination and male sex differentiation. Vitamins and Hormones 70 387-413.

Vilain E \& McCabe ER 1998 Mammalian sex determination: from gonads to brain. Molecular Genetics and Metabolism 65 74-84.

Vreughenhil HJI, Slijper FME, Mulder PGH \& Weisglas-Kuperus N 2002 Effects of perinatal exposure to PCBs and Dioxins on play behavior in Dutch children at school age. Environmental Health Perspectives 110 A593-A598.

Wagner CK, Xu J, Pfau JL, Quadros PS, De Vries GJ \& Arnold AP 2004 Neonatal mice possessing an Sry transgene show a masculinized pattern of progesterone receptor expression in the brain independent of sex chromosome status. Endocrinology 145 1046-1049.

Ward IL, Ward OB, Affuso JD, Long WD, French JA \& Hendricks SH 2003 Fetal testosterone surge: specific modulations induced in male rats by maternal stress and/or alcohol consumtion. Hormones and Behavior 43 531-539.

Weisz J \& Ward IL 1980 Plasma testosterone and progesterone titers of pregnant rats, their male and female fetuses, and neonatal offspring. Endocrinology 106 306-316.

Willoughby KN, Sarkar AJ, Boyadjieva NI \& Sarkar DK 2005 Neonatally administered tert-octylphenol affects onset of puberty and reproductive development in female rats. Endocrine $\mathbf{2 6}$ 161-168.

Wilson JD 1999 The role of androgens in male gender role behavior. Endocrine Reviews 20 726-737.

Wilson CA, Pearson JR, Hunter AJ, Tuohy PA \& Payne AP 1986 The effect of neonatal manipulation of hypothalamic serotonin levels on sexual activity in the adult rat. Pharmacology, Biochemistry and Behaviour 24 1175-1183.

Wilson CA, Gonzalez MI, Albonetti E \& Farabollini F 1998 The involvement of neonatal $5 \mathrm{HT}$ receptor mediated effects on sexual dimorphism of adult behaviours in the rat. In Males, females and behavior: toward biological understanding, pp 109-127. Eds L Ellis \& L Ebertz. Westport USA: Praeger. 
Wisniewski AB 1998 Sexually-dimorphic patterns of cortical asymmetry, and the role for sex steroid hormones in determining cortical patterns of lateralization. Psychoneuroendocrinology 23 519-547.

Wisniewski AB, Cernetich A, Gearhart JP \& Klein SL 2005 Perinatal exposure to genistein alters reproductive development and aggressive behaviour in male mice. Physiology and Behavior 84 327-334.

Witelson SF \& Nowakowski RS 1991 Left hand axons make men right: a hypothesis for the origin of handedness and functional asymmetry. Neuropsychologia 29 327-333.

Yamamoto M, Shirai M, Tamura A, Kobayashi T, Kohara S, Murakami M \& Arishima K 2005 Effects of maternal exposure to a low dose of diethylstilbestrol on sexual dimorphic nucleus volume and male reproductive system in rat offspring. Journal of Toxicological Science 30 7-18.

Zanisi M \& Martini L 1975 Differential effects of castration on LH and FSH secretion in male and female rats. Acta Endocrinologica 78 683-688.
Zareba G, Hojo R, Zareba KM, Watanabe C, Markowski VP, Baggs RB \& Weiss B 2002 Sexually dimorphic alterations of brain cortical dominance in rats prenatally exposed to TCDD. Journal of Applied Toxicology 22 129-137.

Zhang F-P, Poutanen M, Wilbertz J \& Huhtaniemi I 2001 Normal prenatal but arrested postnatal sexual development of luteinizing hormone receptor knockout (LuRKO) mice. Molecular Endocrinology 15 172-183.

Zup SL, Carrier H, Waters EM, Tabor A, Bengston L, Rosen GJ, Simerly RB \& Forger NG 2003 Overexpression of Bcl-2 reduces sex differences in neuron number in the brain and spinal cord. Journal of Neuroscience 23 2357-2362.

Received 22 June 2006

First decision 14 August 2006

Revised manuscript received 11 December 2006

Accepted 18 December 2006 